\title{
Immuno-EM characterization of vasopressin neurons in macaques by use of formaldehyde-fixed tissues stored for several years
}

Akito Otubo $^{1}$, Sho Maejima ${ }^{1}$, Takumi Oti ${ }^{1,2}$, Keita Satoh $^{1,3}$, Yasumasa Ueda ${ }^{4,5}$, John F.

Morris $^{6}$, Tatsuya Sakamoto ${ }^{1}$, and Hirotaka Sakamoto ${ }^{1,6 *}$

${ }^{1}$ Ushimado Marine Institute (UMI), Graduate School of Natural Science and Technology, Okayama University, Ushimado, Setouchi, Okayama 701-4303, Japan

${ }^{2}$ Department of Biological Sciences, Faculty of Science, Kanagawa University, Hiratsuka,

10 Kanagawa 259-1293, Japan

${ }^{3}$ Department of Anatomy, Kawasaki Medical School, Kurashiki, Okayama 701-0192, Japan

${ }^{4}$ Department of Physiology, Kyoto Prefectural University of Medicine, Kyoto 602-8566, Japan

${ }^{5}$ Department of Physiology, Kansai Medical University, Shinmachi, Hirakata, Osaka 573-

15 1191, Japan

${ }^{6}$ Department of Physiology, Anatomy \& Genetics, University of Oxford, South Parks Road, Oxford OX1 3QX, UK

\section{*Correspondence:}

20 Hirotaka Sakamoto, Ph.D.

Ushimado Marine Institute (UMI), Graduate School of Natural Science and Technology, Okayama University, 130-17 Kashino, Ushimado, Setouchi, Okayama 701-4303, Japan.

E-mail: hsakamo@,okayama-u.ac.jp

\section{CONFLICT OF INTERESTS}

The authors declare that they have no conflicts of interest. 


\begin{abstract}
(189/200 words):
Translational research often requires the testing of experimental therapies in primates, but research in non-human primates is now stringently controlled by law around the world.

5 Tissues fixed in formaldehyde without glutaraldehyde have been thought to be inappropriate for use in electron microscopic analysis, particularly those of the brain. Here we report the immunoelectron microscopic characterization of arginine vasopressin (AVP)-producing neurons in macaque hypothalamo-pituitary axis tissues fixed with $4 \%$ formaldehyde and stored at $-25^{\circ} \mathrm{C}$ for several years. The size difference of dense-cored vesicles between

10 magnocellular and parvocellular AVP neurons was detectable in their cell bodies and perivascular nerve endings located, respectively, in the posterior pituitary and median eminence. Furthermore, glutamate and the vesicular glutamate transporter 2 were colocalized with AVP in perivascular nerve endings of both the posterior pituitary and the external layer of the median eminence, suggesting that both magnocellular and parvocellular AVP neurons

15 are glutamatergic in primates. Both ultrastructure and immunoreactivity can therefore be sufficiently preserved in macaque brain tissues stored long-term for light microscopy. Taken together, these results suggest that this methodology could be applied to the human postmortem brain and be very useful in translational research.
\end{abstract}

\title{
20 KEYWORDS:
}

Vasopressin; corticotrophin-releasing factor; glutamate; paraventricular nucleus of the hypothalamus; Japanese macaque monkey; post-embedding immunoelectron microscopy, dense-cored neurosecretory vesicle 


\section{Introduction}

Studies using macaque monkeys as model non-human primates are essential because of their high applicability to human clinical research which often requires the testing of

5 experimental therapies in primates. However, primate research is now stringently controlled by law around the world (Abbott, 2014). Rodents, in which research is less restricted, are often not analogous enough to humans in their physiology to allow an extrapolation from rodent to human. Medical science is urged to make minimal use of animals such as primates, and basic studies on non-human primates appear to be permitted only if the work could not

10 be carried out in any other species. Thus, although tissues from primates are often essential to achieve relevant results, there are, nevertheless, considerable problems in their use.

Arginine vasopressin (AVP), an anti-diuretic hormone, is released, not only into the blood stream, but also into the central nervous system where, in mammals, it has been shown to be important for stress coping, aggression, courtship behavior, learning, bonding, and

15 various socio-sexual behaviors (Walum \& Young, 2018). AVP is produced mainly by magnocellular neurosecretory neurons in the supraoptic nucleus (SON) and paraventricular nucleus (PVN) of the hypothalamus (Buijs et al., 1983). The AVP gene encodes a precursor containing AVP, AVP-associated neurophysin II (NPII), and a glycopeptide copeptin (Breslow, 1993; Davies et al., 2003; Land et al., 1982). The expression and release of AVP by

20 magnocellular neurosecretory neurons in the SON and PVN are regulated by physiological conditions, including plasma osmotic pressure and blood pressure (Koshimizu et al., 2012). The magnocellular axons project primarily via the internal layer of the median eminence to the posterior pituitary where they release AVP into the systemic circulation. In addition, some parvocellular neurons in the PVN produce AVP and project into extrahypothalamic areas 
where the AVP and/or other co-packaged molecules regulate brain function as neuromodulators (Morris, 2020).

Corticotrophin-releasing factor (CRF) is a strong stimulator of adrenocorticotrophic hormone $(\mathrm{ACTH})$ secretion from the anterior pituitary when released onto portal capillaries

5 in the median eminence in response to the stress (Vale et al., 1981). A population of parvocellular neurons in the anteromedial part of the PVN produces CRF and may, depending on the extent of stress, also produce AVP. Both peptides released into the hypothalamohypophysial portal circulation play an important synergistic role in stress resilience (Fellmann et al., 1984; Itoi et al., 2014; Mouri et al., 1993; Whitnall et al., 1985). Because

10 intense AVP- and CRF-immunoreactivity have been observed in the external layer of the macaque median eminence, the peptides are probably co-released into the portal circulation to amplify ACTH release from the primate anterior pituitary (Otubo et al., 2020; Zimmerman et al., 1973).

In rodents, the presence of glutamate-immunoreactivity in magnocellular

15 neuroendocrine cells of the SON suggests that AVP neurons also produce glutamate as a neurotransmitter (Meeker et al., 1991; Meeker et al., 1989). Within the neurosecretory endings of the posterior pituitary, glutamate immunoreactivity is specifically localized to electron-lucent microvesicles with no overlap onto the dense-cored neurosecretory vesicle (dcv) population in rats (Meeker et al., 1991). Immunocytochemical co-localization of CRF

20 and the vesicular glutamate transporter 2 (VGLUT2) in rats suggests that the co-release of CRF and glutamate may function to regulate postsynaptic targets (Valentino et al., 2001). It is currently unclear whether glutamate has a similar or other functions in the primate AVP/CRF system.

Tissues fixed in formaldehyde without glutaraldehyde have long been thought to be 25 inappropriate for use in electron microscopic analysis, especially in the brain (Maunsbach, 
1966a, 1966b). Here we report the immunoelectron microscopic characterization of AVPproducing neurons in the primate hypothalamo-pituitary axis tissue fixed with formaldehyde and stored at $-25^{\circ} \mathrm{C}$ for several years. Special attention was paid to the size of dcv in AVPproducing magno- and parvocellular neurons and to the colocalization of CRF with AVP-

5 related gene products in the dcv. We show that immunoelectron microscopy of formaldehydefixed tissue can confirm the size difference in dev between magno- and parvocellular AVP neurons in Japanese macaque monkeys. Furthermore, we show that, in macaque monkeys, AVP/CRF and the VGLUT2/glutamate are co-localized in both the magnocellular endings of the posterior pituitary and the parvocellular endings in the external layer of the median eminence.

\section{Results}

15 2.1. Antibody characterization and the expression of VGLUT2 at the protein level in the posterior pituitary

Full details of all the antibodies used in this study are shown in Table 1. We first validated by Western blot analysis the specificity for the VGLUT2 and NPII antibodies in Japanese macaque monkeys. Western blot analysis demonstrated the specificity for the guinea

20 pig polyclonal antibody against VGLUT2 and the expression of VGLUT2 at the protein level in the posterior pituitary; a single strong immunoreactive band was detected at the expected molecular weight of $\sim 56 \mathrm{kDa}$ (Balaram et al., 2013) (Fig. 1). The mouse monoclonal antibody against AVP-neurophysin II (NPII) also detected a single major band at the expected molecular weight of $\sim 12 \mathrm{kDa}$ on the blots of posterior pituitary (Kawakami et al., 2021;

25 Otubo et al., 2020) (Fig. 1). 


\subsection{Anatomy of AVP-producing neurons in the macaque hypothalamus}

Immunostaining for NPII was performed to study the localization of AVP neurons in the hypothalamus of Japanese macaque monkeys. Numerous magnocellular (large-sized)

5 AVP neurons were observed in the PVN (Fig. 2A) and SON (Fig. 2B). Parvocellular (smallsized) AVP neurons were also observed in the PVN (Fig. 2C). The median eminence can be divided into an internal and an external layer. The internal layer is the zone through which the axons of magnocellular neurons densely project into the posterior pituitary (Fig. 2D) (Buijs et al., 1983; Morris, 2020; Zimmerman et al., 1973). The external layer of the median eminence

10 is where the axons of many parvocellular neurosecretory neurons, including parvocellular AVP/CRF neurons of the PVN, end on hypothalamo-hypophysial portal vessels and release anterior pituitary-hormone-regulating hormones (Fig. 2D) (Buijs et al., 1983; Morris, 2020; Zimmerman et al., 1973).

Immunoelectron microscopy of the posterior pituitary showed many AVP dcv

15 containing both NPII (PS41)- and copeptin (CP8)-immunoreactivity (Fig. 3A, B). In other neighbouring endings, no NPII- or copeptin-immunoreactivity was detectable (Fig. 3C). In the median eminence, many dcv showing PS41/CP8 double-immunoreactivity were observed in both the internal and external layers (Fig. 4). However, the AVP dcv in the internal layer (magnocellular) of the median eminence (Fig. 4B) were larger than those in the external layer

20 (parvocellular) of the median eminence (Fig. 4D).

\subsection{Size characterization of $d c v$}

In this study, immunoelectron microscopic characterization of AVP-producing neurons was performed in macaque hypothalamo-pituitary axis tissues fixed with $4 \%$

25 formaldehyde and stored at $-25^{\circ} \mathrm{C}$ for several years. We found that both ultrastructure and 
immunoreactivity are sufficiently preserved in macaque brain tissues stored long-term for light microscopy. Approximately $200 \mathrm{dcv}$ in the neurosecretory axons in the posterior pituitary (magnocellular), the internal layer of the median eminence (magnocellular), and the external layer of the median eminence (parvocellular) were selected and their major axis

5 diameters were measured. The average of major axis was $196 \pm 2 \mathrm{~nm}$ in the posterior pituitary, $197 \pm 2 \mathrm{~nm}$ in the internal layer of the median eminence, but significantly smaller $(93 \pm 1 \mathrm{~nm})$ in the external layer of the median eminence (Fig. 5; Table 2).

Next, we measured the diameter of dcv in the perikarya of randomly selected SON and PVN AVP neurosecretory neurons (at x5,000 magnification; Table 3). In the SON (7 cell bodies), the average diameter of dcv contained in the cell body was $204 \pm 12 \mathrm{~nm}$ (11 vesicles), confirming that, as expected, all AVP neurons in the SON are magnocellular (Fig. 6; Table 3). The 18 AVP neurons in the PVN selected for analysis formed two distinct groups: those with larger dcv (180 \pm 19 nm; 11 vesicles; Fig. 7A, B) identified as magnocellular; and those with smaller dev (102 $\pm 10 \mathrm{~nm}$; 14 vesicles; Fig. 7C, D) identified as parvocellular neurons.

\subsection{A subpopulation of parvocellular AVP neurons in the PVN co-expresses CRF}

In the PVN, of the 18 AVP neuronal cell bodies analyzed, 6 were identified as magnocellular on the basis of vesicle size; none of these showed any CRF-immunoreactivity. Of the 12 PVN perikarya identified as parvocellular on the basis of vesicle size, a

20 subpopulation (especially in the parvocellular part of the PVN) co-expressed CRF (Fig. 8) and such neurons were more intermingled with magnocellular neurons in the macaque monkey than in rodent PVN as reported previously (Foote \& Cha, 1988; Kawata \& Sano, 1982; Otubo et al., 2020). The terminal regions of parvocellular AVP/CRF neurons in the external layer of the median eminence were next analyzed (Fig. 9). In these cells, the major 25 axis diameter of the sparse dcv was $106 \pm 3 \mathrm{~nm}$ (16 vesicles) (Fig. 10) for the vesicles in the 
CRF-immunoreactive terminals, comparable to the $113 \pm 9 \mathrm{~nm}$ (12 vesicles) in the cell body

(Fig. 11). In two putative parvocellular neurons (\#24 and \#25), the mean major axis of the dcv appeared slightly larger which might relate to the maturity of the vesicles (Table 3)

(Cannata \& Morris, 1973).

5

\subsection{Both magno- and parvocellular AVP neurons are glutamatergic}

We first performed immunoelectron microscopy for L-glutamate in the posterior pituitary in order to determine its occurrence in the terminal regions of magnocellular AVP neurons. The immunoreactivity for glutamate was associated primarily with the membrane of

10 small electron-lucent vesicles in the axonal endings of AVP neurons of posterior pituitary (Fig. 12A, B). In contrast, NPII-immunoreactivity was associated with dcv (Fig. 12A, B). Next, we examined the terminal regions of parvocellular axons in the median eminence. Triple staining for CRF/NPII/glutamate (Fig. 12C, D) showed that, as in the posterior pituitary, glutamateimmunoreactivity was associated with the membrane of electron-lucent microvesicles in the

15 parvocellular endings which contained AVP/CRF-positive dev (Fig. 12C, D) and in other similar endings of the terminals of other parvocellular neurosecretory neurons. Due to the mild formaldehyde fixation, the membrane of single microvesicles could not be clearly distinguished. However, a comparison with glutaraldehyde-fixed material leaves no doubt that these are clusters of microvesicles. Similar results were obtained by immunoelectron

20 microscopy for VGLUT2 in both the posterior pituitary and the external layer of the median eminence (Fig. 13).

\section{Discussion}


It is often assumed that glutaraldehyde, a cross-linking fixative, is essential for the preservation of fine ultrastructure (Maunsbach, 1966a, 1966b) and that formaldehyde-only fixed tissues are inappropriate for electron microscopic analyses. However, the use of glutaraldehyde often results in a reduction of immunoreactivity and, for this reason,

5 formaldehyde-fixed tissues without glutaraldehyde are used in most cases for immunohistochemical analysis at the light microscopic level (Maunsbach, 1966a, 1966b). The current study demonstrates that, in the macaque brain, interpretable ultrastructure and adequate ultrastructural immunoreactivity are both preserved in brain tissue even after longterm storage at $-25^{\circ} \mathrm{C}$ for conventional light microscopy, provided that the fixed tissues are

10 post-fixed with glutaraldehyde after the long-term storage. Thus, formalin-fixed macaque brains stored for a long period, at least 5-years, can be used for immunoelectron microscopic analysis, suggesting that not only macaque brain, but also postmortem formalin-fixed human brain tissue could be amenable to immunoelectron microscopic analysis. Furthermore, the ultrastructure of tissues from rare animals such as endangered species might be studied in this way even if they had been prepared for light microscopic immunohistochemistry and stored at $-25^{\circ} \mathrm{C}$ in antifreeze solution.

The methodology used in this study has some obvious advantages in the ultrastructural analysis of the nervous system, in which tissue specimens are necessarily small, particularly where the brain is large, as in macaque monkeys and humans. After confirmation

20 of the specificity of antibodies at the light microscopic level, post-embedding immunoelectron microscopic analysis can readily be performed on adjacent sections. Furthermore, because identification of brain nuclei and/or cells is easier at the light microscopic level, they can then be precisely targeted for post-embedding immunoelectron microscopy. 
It has been reported that rodent AVP neurons also use glutamate as a neurotransmitter (Meeker et al., 1991; Meeker et al., 1989; Zhang et al., 2020; Ziegler et al., 2002). In this study, we examined the expression of glutamate and VGLUT2 in the macaque posterior pituitary. We first demonstrated by Western blotting that VGLUT2 was expressed in the macaque posterior pituitary, suggesting that magnocellular AVP (and also oxytocin) neurons use glutamate as a neurotransmitter in Japanese macaque monkeys. Immunoelectron microscopic analysis revealed that the AVP/CRF-immunoreactivity was restricted to the dcv, but the VGLUT2-immunoreactivity was associated with the smaller, electron-lucent microvesicles (Fig. 14). Similarly, immunoreactivity for glutamate itself was essentially

10 restricted to microvesicles in the axonal endings of AVP neurons in both the posterior pituitary and external layer of the median eminence (Fig. 14). Because the antibody for glutamate, an amino acid, is raised against the cross-linking site of glutaraldehyde as the antigen, it is thought to be essential that glutaraldehyde is included in the fixative prior to glutamate immunocytochemistry (Meeker et al., 1991; Meeker et al., 1989; Sun et al., 2007).

15 In our study, although glutaraldehyde was not included in the primary perfusion fixative, post-fixation of the formaldehyde-fixed tissue with glutaraldehyde enabled us to detect glutamate by immunoelectron microscopy even after prolonged storage. Therefore, the subcellular localization of amino acids appears to be preserved for a long-term even with conventional formaldehyde fixation. The immunoelectron microscopic detection of amino

20 acids including glutamate and GABA should also be possible in conventional formaldehydefixed and stored human brain tissue.

Our results in macaque tissue show that glutamate as an excitatory neurotransmitter is in microvesicles both in magno- and parvocellular AVP neurons. Although the localization of glutamate receptors has been reported in the neural lobe, median eminence and anterior 25 pituitary, a clear role for glutamate secretion at these sites remains unknown (Brann, 1995; 
Hrabovszky \& Liposits, 2007). Salt loading has been shown to produce robust increases in the VGLUT2 mRNA of AVP neuron perikarya and in VGLUT2-immunoreactivity in the rat posterior pituitary (Hrabovszky et al., 2006), suggesting that an osmotic challenge could produce an increase in glutamate release in the primate magnocellular AVP system (Fig. 14).

5 Similarly, a role in the anterior pituitary of glutamate released from parvocellular AVP/CRF neurons into the hypothalamo-hypophysial portal veins remains unclear. Functional implications for glutamate release at the terminals of both magno- and parvocellular AVP neurons remain to be explored.

The size of dev contained in the terminals of AVP neurons was quantified and 10 compared among the posterior pituitary and internal/external layers of the median eminence. This showed, also for the macaque, the expected significant difference in size of the dcv (Fig. 14). It is known that the posterior pituitary and the internal layer of the median eminence contain the axons of magnocellular AVP neurons of the PVN and SON, whereas the external layer of the median eminence is the terminal region of parvocellular AVP neurons of the PVN

15 (Buijs et al., 1983; Morris, 2020; Zimmerman et al., 1973) and other parvocellular neurons influence the anterior pituitary. In the dcv of the internal layer of the median eminence through which the magnocellular axons pass en route to the posterior pituitary, the AVP precursor should be processed sufficiently to reveal both prominent NPII- and copeptinimmunoreactivity in almost all of the axons (Kawata \& Sano, 1982; Otubo et al., 2020;

20 Zimmerman et al., 1973). In the macaque hypothalamus, quantifying only the size of the dcv in the cell body or its axon allows us to determine the magnocellular or parvocellular identify of the cell. Finally, our study confirms at the electron microscopic level that certain axonal endings in the external layer of the median eminence of macaques are derived from parvocellular AVP neurons of the PVN. 


\section{Conclusions}

We report the immunoelectron microscopic characterization of AVP-producing neurons in primate hypothalamo-pituitary systems by the use of formaldehyde-fixed tissues

$5 \quad$ stored at $-25^{\circ} \mathrm{C}$ for several years. The size difference in dev between magno- and parvocellular AVP neurons in Japanese macaque monkeys was determined (Fig. 14). We also demonstrate by immunoelectron microscopy that both magno- and parvocellular AVP neurons are glutamatergic in primates (Fig. 14). These results show, for the macaque brain, that interpretable neuronal ultrastructure and sufficient immunoreactivity for several relevant

10 proteins are preserved even after a long-term storage of tissues fixed in formaldehyde for light microscopy. They indicate that this methodology could be applied to human postmortem brain and, therefore, be very useful in translational research.

\section{5. Materials and Methods}

\subsection{Animals}

Three male (2-9-year-old, weight 2.3-12.6 kg) and four female (9-11-year-old, weight 7.2-10.8 kg) Japanese macaque monkeys (Macaca fuscata) were used in this study.

20 Macaques were maintained in a temperature-controlled $\left(22-24^{\circ} \mathrm{C}\right)$ room under a daily photoperiod of 12:12 hour light/dark cycle (lights off at 8:00 p.m.). These animals were checked and shown to be free of specific pathogens. Food and water were available ad libitum. All animals were kept in individual cages. The housing and experimental protocols followed the guidelines of the Ministry of Education, Culture, Sports, Science, and

25 Technology (MEXT) of Japan, and were in accordance with the Guide for the Care and Use 
of Laboratory Animals prepared by Okayama University (Okayama, Japan), by Tokyo Medical and Dental University (Tokyo, Japan), and by National Institute for Physiological Sciences (Okazaki, Japan). All efforts were made to minimize animal suffering and reduce the number of animals used in this study.

\subsection{Tissue processing}

Hypothalamic sections and posterior pituitaries were obtained from four macaque monkeys ( 2 females and 2 males) as described previously (Otubo et al., 2020). Briefly, macaques were deeply anaesthetized with an overdose of sodium pentobarbital $(\sim 100 \mathrm{mg} / \mathrm{kg}$ body weight), and transcardially perfused with physiological saline followed by $4 \%$ paraformaldehyde (PFA) in 0.1 M phosphate buffer (PB, pH 7.4). After perfusion, brains and pituitaries were immediately removed and immersed in the same fixative for $\sim 16$ hours at $4^{\circ} \mathrm{C}$. Coronal $30-\mu$ m-thick sections of the hypothalamus were prepared with a Linear-Slicer (PRO10, Dosaka EM, Kyoto, Japan). Preparations were rinsed with PB and then immersed in antifreeze solution (30\% glycerol, $30 \%$ ethylene glycol, $0.36 \% \mathrm{NaCl}$, and $0.05 \% \mathrm{NaN}_{3}$ in 40 $\mathrm{mM}$ PB) for storage at $-25^{\circ} \mathrm{C}$ until use. For Western blot analysis, three female macaques were sacrificed by blood loss under deep pentobarbital anesthesia (see above). Posterior pituitaries were quickly removed, frozen immediately in powdered dry ice, and stored at $80^{\circ} \mathrm{C}$ until use.

\subsection{Immunofluorescence}

The stored, formaldehyde-fixed sections were rinsed with phosphate-buffered saline (PBS) containing $0.3 \%$ Triton X-100 (PBST) five times for 10 minutes each. After blocking nonspecific binding with 1\% normal goat serum and 1\% BSA in PBST for 30 minutes at room temperature, the sections were incubated with mouse monoclonal anti-AVP-NPII 
antibody (PS41; 1:1,000 dilution) and with rabbit antiserum directed against copeptin (1: 10,000 dilution) or with rabbit antiserum directed against CRF (1: 20,000 dilution) for 4-5 days at $4^{\circ} \mathrm{C}$. The mouse monoclonal NPII antibody has previously shown to be specific for AVP neurons in rodents (Castel et al., 1986; Wang et al.) and macaque monkeys (Otubo et al.,

5 2020). The copeptin7-14 (ATQLDGPA) fragment, used as an antigen to produce our copeptin antiserum, is well conserved in mammals. It is identical in rats (Rehbein et al., 1986), mice (Hara et al., 1990), macaque monkeys (Otubo et al., 2020), and humans (Rehbein et al., 1986). The copeptin antiserum has also been characterized previously by our immunohistochemistry (Kawakami et al., 2021), Western (Satoh et al., 2015) and dot blot (Kawakami et al., 2021)

10 analyses. The rabbit polyclonal antiserum against rat/human CRF (PBL rC70), which was kindly donated by Wylie Vale, has been characterized previously (Kawakami et al., 2021; Otubo et al., 2020; Sawchenko et al., 1984). It was directed against the rat form of CRF, which is identical to the human form, and has also been characterized in non-human primates (Foote \& Cha, 1988; Otubo et al., 2020). Alexa Fluor 546-linked goat anti-mouse IgG

15 (Molecular Probes, Eugene, OR, USA) and Alexa Fluor 488-linked goat anti-rabbit IgG (Molecular Probes) were used for detection at 1:1,000 dilution. Immunostained sections were viewed by confocal laser scanning microscopy (FluoView 1000, Olympus, Tokyo, Japan). The information for antibodies used in this study is shown in Table 1.

The stored, formaldehyde-fixed sections were rinsed with PBS five times for 10 minutes each, and re-fixed in 4\% PFA $+0.1 \%$ glutaraldehyde in $0.1 \mathrm{M}$ PB for 4-6 hours at $4^{\circ} \mathrm{C}$. Sections were then rinsed with $0.1 \mathrm{M} \mathrm{PB}$ three times for 5 minutes each, and were dehydrated through increasing concentrations of methanol, flat-embedded in LR Gold resin 25 (Electron Microscopy Sciences, Hatfield, PA, USA) by gently pressing against the bottom of 
the flat-bottom-capsule with a pre-prepared resin block, and polymerized under UV lamps at $-25^{\circ} \mathrm{C}$ for 24 hours. Ultrathin sections (70 $\mathrm{nm}$ in thickness) were collected on nickel grids coated with (or without for triple labeling) a collodion film, rinsed with PBS several times, then incubated with $2 \%$ normal goat serum and $2 \%$ BSA in $50 \mathrm{mM}$ Tris(hydroxymethyl)-

5 aminomethane-buffered saline (TBS; $\mathrm{pH}$ 8.2) for 20 minutes to block non-specific binding. The sections were then incubated with the mouse monoclonal antibody against NPII $(1: 200$ dilution), with the rabbit polyclonal antisera against CRF (1:5,000 dilution), copeptin (1:100 dilution), L-glutamate (1:10 dilution, Abcam, Cambridge, UK), and/or with the guinea pig polyclonal antibody against VGLUT2 (1:20 dilution, Synaptic Systems, Göttingen, Germany)

10 for 1 hour at room temperature. After incubation with the primary antibodies, the sections were washed with PBS, then incubated with a goat antibody against rabbit IgG conjugated to 5 or $10 \mathrm{~nm}$ gold particles (1:50 dilution, BBI Solutions, Cardiff, UK) and a goat antibody against mouse IgG conjugated to $15 \mathrm{~nm}$ gold particles (1:50 dilution, BBI Solutions) and/or a goat antibody against guinea pig $\mathrm{IgG}$ conjugated to $5 \mathrm{~nm}$ gold particles (1:50 dilution,

15 Nanoprobes, Yaphank, NY, USA) for 1 hour at room temperature. The Abcam antibody to glutamate was raised in rabbit against L-glutamate conjugated to glutaraldehyde as the immunogen. The manufacturer's information shows no measurable cross-reactivity detected against glutamate in peptides or proteins but modest cross-reactivity against D-glutamate. The specificity of this antibody was confirmed by immunostaining in the rat retina (Sun et al.,

20 2007). To intensify the detectability of the immunoreaction for CRF in the cell body, a streptavidin-biotin intensification kit (Nichirei, Tokyo, Japan) was used. Tissues were first incubated with the biotinylated goat anti-rabbit IgG antibody for 10 minutes at room temperature, followed by incubation in avidin-biotin-horseradish peroxidase (HRP) complex solution for 5 minutes at room temperature. The sections were then washed with PBS, 25 incubated with the goat antibody against HRP conjugated to $6 \mathrm{~nm}$ gold particles $(1: 50$ 
dilution, Jackson ImmunoResearch Laboratory, West Grove, PA, USA) for 1 hour at room temperature.

Triple immunoelectron microscopy with antibodies against CRF, NPII, and glutamate was performed by using the front and back of ultrathin sections mounted on nickel grids

5 without a supporting film. First, immunocytochemistry with a pair of primary antibodies (CRF and NPII) was performed on one side of the section and detected using $15 \mathrm{~nm}$ (mouse) and $10 \mathrm{~nm}$ (rabbit) colloidal gold particles (BBI Solutions), respectively. Next, immunocytochemistry with the other primary rabbit antibody (against glutamate) was performed on the other side of the section and detected by use of $5 \mathrm{~nm}$ colloidal gold particles

10 (BBI Solutions).

Finally, the sections were contrasted with uranyl acetate and lead citrate and viewed using an H-7650 (Hitachi, Tokyo, Japan) or JEM-1010 (JEOL, Tokyo, Japan) electron microscope operated at $80 \mathrm{kV}$. The information for antibodies used in this study is shown in Table 2.

\subsection{Western blotting}

The lysates derived from posterior pituitaries were boiled in $10 \mu 1$ sample buffer containing $62.5 \mathrm{mM}$ trishydroxymethyl-aminomethane- $\mathrm{HCl}$ (Tris-HCl; $\mathrm{pH}$. 6.8), 2\% SDS, $25 \%$ glycerol, $10 \%$ 2-mercaptoethanol, and a small amount of bromophenol blue. These samples were run on a 4-20\% SDS-PAGE and electroblotted onto a polyvinylidene difluoride (PVDF) membrane (Bio-Rad Laboratories, Hercules, CA, USA) from the gel by a semidry blotting apparatus (Bio-Rad Laboratories). The blotted membranes were blocked with PVDF Blocking Reagent for Can Get Signal (TOYOBO, Tokyo, Japan) for 30 minutes at room temperature and incubated overnight at $4^{\circ} \mathrm{C}$ with anti-AVP-NPII mouse monoclonal antibody (PS41) $(1: 1,000)$ or anti-VGLUT2 guinea pig polyclonal antibody $(1: 10,000)$ in Can Get 
Signal Solution 1 (TOYOBO). The blotted membranes were rinsed three times with $0.05 \%$

Tween 20 in Tris-HCl-buffered saline (TBST) and incubated with horseradish peroxidaseconjugated goat polyclonal antibody against mouse IgG (Bio-Rad Laboratories) or guinea pig IgG (Bioss Inc., Woburn, MA, USA) 1:10,000 dilution in Can Get Signal Solution 2

5 (TOYOBO) for 1 hour at room temperature. After washing for three times with TBST, blots were visualized by Immun-Star WesternC Chemiluminescence Kit (Bio-Rad Laboratories). The information for antibodies used in this study is shown in Table 2.

\subsection{Statistical analysis}

All data values were expressed as mean \pm standard error of the mean (SEM).

Statistical significance was determined as $P<0.05$ using one-way analysis of variance (ANOVA). When significant difference was found by ANOVA, the post hoc Tukey-Kramer test was performed. All the various analyses in this study were conducted "blind".

Author Contributions: Conceptualization, H.S.; methodology, A.O., S.M., T.O., K.S. and H.S.; validation, A.O. and H.S.; formal analysis, A.O. and H.S.; investigation, A.O., S.M., T.O., K.S. and H.S.; resources, T.O., K.S., Y.U. and H.S.; writing - original draft preparation, H.S.; writing-review and editing, J.F.M.; interpreted the data and provided advice and equipment, Y.U., J.F.M. and T.S.; supervision and project administration, H.S.; funding acquisition, T.O. and H.S. All authors have read and agreed to the published version of the manuscript.

Funding: This work was supported by Grants-in-Aid for Scientific Research from the Japan 25 Society for the Promotion of Science (JSPS) KAKENHI [to H.S.; 15K15202, 15H05724, 15KK025708, 16H06280 (ABiS); to T.O.; 20K15837]. T.O. and K.S. were supported by Research Fellowships of JSPS for Young Scientists.

Acknowledgments: Tissues of Nihonzaru (Japanese macaque monkeys) were provided by 30 National Institutes of Natural Sciences (NINS) and Kyoto University Primate Research Institute (KUPRI) with support in part by the National Bio-Resource Project (NBRP) of the Ministry of Education, Culture, Sports, Science and Technology (MEXT), Japan. We thank Dr. Narumi Katsuyama (Tokyo Medical and Dental University, Japan), Kei Tamaura and Ray 
Nomura for their technical support. We are grateful to Dr. Wylie Vale for the supply of an antiserum against CRF.

Conflicts of Interest: The authors declare no conflict of interest.

5
Abbreviations
ANOVA, analysis of variance; AVP, arginine vasopressin; CRF, corticotrophin-releasing factor; dcv, dense-cored neurosecretory vesicle; HRP, horseradish peroxidase; NP, neurophysin; PB, phosphate buffer; PBS, phosphate-buffered saline; PFA, paraformaldehyde; PVDF, polyvinylidene difluoride; PVN, paraventricular nucleus; SEM, standard error of the mean; SON, supraoptic nucleus; Tris- $\mathrm{HCl}$, trishydroxymethyl-aminomethane-HCl; TBST, Tris-HCl-buffered saline; VGLUT2, vesicular glutamate transporter 2. 


\section{References}

Abbott, A. (2014). Biomedicine: the changing face of primate research. Nature, 506(7486), 24-26. https://doi.org/10.1038/506024a

Balaram, P., Hackett, T. A., \& Kaas, J. H. (2013). Differential expression of vesicular glutamate transporters 1 and 2 may identify distinct modes of glutamatergic transmission in the macaque visual system. J Chem Neuroanat, 50-51, 21-38. https://doi.org/10.1016/j.jchemneu.2013.02.007

Brann, D. W. (1995). Glutamate: a major excitatory transmitter in neuroendocrine regulation. Neuroendocrinology, 61(3), 213-225. https://doi.org/10.1159/000126843

10 Breslow, E. (1993). Structure and folding properties of neurophysin and its peptide complexes: biological implications. Regul Pept, 45(1-2), 15-19. http://www.ncbi.nlm.nih.gov/pubmed/8511339

Buijs, R. M., De Vries, G. J., Van Leeuwen, F. W., \& Swaab, D. F. (1983). Vasopressin and oxytocin: distribution and putative functions in the brain. Prog Brain Res, 60, 115-122. https://doi.org/10.1016/S0079-6123(08)64379-4

Cannata, M. A., \& Morris, J. F. (1973). Changes in the appearance of hypothalamoneurohypophysial neurosecretory granules associated with their maturation. $J$ Endocrinol, 57(3), 531-538. https://doi.org/10.1677/joe.0.0570531

Castel, M., \& Morris, J. F. (1988). The neurophysin-containing innervation of the forebrain of the mouse. Neuroscience, 24(3), 937-966. https://doi.org/10.1016/0306$\underline{4522(88) 90078-4}$

Castel, M., Morris, J. F., Whitnall, M. H., \& Sivan, N. (1986). Improved visualization of the immunoreactive hypothalamo-neurohypophysial system by use of immuno-gold techniques. Cell Tissue Res, 243(1), 193-204. http://www.ncbi.nlm.nih.gov/pubmed/2417720

Davies, J., Waller, S., Zeng, Q., Wells, S., \& Murphy, D. (2003). Further delineation of the sequences required for the expression and physiological regulation of the vasopressin gene in transgenic rat hypothalamic magnocellular neurones. J Neuroendocrinol, 15(1), 42-50. https://doi.org/865 [pii]

30 Fellmann, D., Bugnon, C., Bresson, J. L., Gouget, A., Cardot, J., Clavequin, M. C., \& Hadjiyiassemis, M. (1984). The CRF neuron: immunocytochemical study. Peptides, 5 Suppl 1, 19-33. http://www.ncbi.nlm.nih.gov/pubmed/6207509 
Foote, S. L., \& Cha, C. I. (1988). Distribution of corticotropin-releasing-factor-like immunoreactivity in brainstem of two monkey species (Saimiri sciureus and Macaca fascicularis): an immunohistochemical study. J Comp Neurol, 276(2), 239-264. https://doi.org/10.1002/cne.902760208

5 Frahm, S., Antolin-Fontes, B., Gorlich, A., Zander, J. F., Ahnert-Hilger, G., \& Ibanez-Tallon, I. (2015). An essential role of acetylcholine-glutamate synergy at habenular synapses in nicotine dependence. Elife, 4, e11396. https://doi.org/10.7554/eLife.11396

Hara, Y., Battey, J., \& Gainer, H. (1990). Structure of mouse vasopressin and oxytocin genes. Brain Res Mol Brain Res, 8(4), 319-324. https://www.ncbi.nlm.nih.gov/pubmed/2176709

Hou, S., Duale, H., Cameron, A. A., Abshire, S. M., Lyttle, T. S., \& Rabchevsky, A. G. (2008). Plasticity of lumbosacral propriospinal neurons is associated with the development of autonomic dysreflexia after thoracic spinal cord transection. J Comp Neurol, 509(4), 382-399. https://doi.org/10.1002/cne.21771

15 Hrabovszky, E., Csapo, A. K., Kallo, I., Wilheim, T., Turi, G. F., \& Liposits, Z. (2006). Localization and osmotic regulation of vesicular glutamate transporter-2 in magnocellular neurons of the rat hypothalamus. Neurochem Int, 48(8), 753-761. https://doi.org/10.1016/j.neuint.2005.12.013

Hrabovszky, E., \& Liposits, Z. (2007). Glutamatergic phenotype of hypothalamic neurosecretory systems: a novel aspect of central neuroendocrine regulation. Ideggyogy Sz, 60(3-4), 182-186. https://www.ncbi.nlm.nih.gov/pubmed/17451065

Itoi, K., Talukder, A. H., Fuse, T., Kaneko, T., Ozawa, R., Sato, T., Sugaya, T., Uchida, K., Yamazaki, M., Abe, M., Natsume, R., \& Sakimura, K. (2014). Visualization of corticotropin-releasing factor neurons by fluorescent proteins in the mouse brain and characterization of labeled neurons in the paraventricular nucleus of the hypothalamus. Endocrinology, 155(10), 4054-4060. https://doi.org/10.1210/en.2014-1182

Kawakami, N., Otubo, A., Maejima, S., Talukder, A. H., Satoh, K., Oti, T., Takanami, K., Ueda, Y., Itoi, K., Morris, J. F., Sakamoto, T., \& Sakamoto, H. (2021). Variation of pro-vasopressin processing in parvocellular and magnocellular neurons in the paraventricular nucleus of the hypothalamus: Evidence from the vasopressin-related glycopeptide copeptin. $J$ Comp Neurol, 529, 1372-1390. https://doi.org/10.1002/cne.25026 
Kawata, M., \& Sano, Y. (1982). Immunohistochemical identification of the oxytocin and vasopressin neurons in the hypothalamus of the monkey (Macaca fuscata). Anat Embryol

(Berl),

$165(2)$

151-167.

http://www.ncbi.nlm.nih.gov/pubmed/7158807

5 Koshimizu, T. A., Nakamura, K., Egashira, N., Hiroyama, M., Nonoguchi, H., \& Tanoue, A. (2012). Vasopressin V1a and V1b receptors: from molecules to physiological systems. Physiol Rev, 92(4), 1813-1864. https://doi.org/10.1152/physrev.00035.2011

Land, H., Schutz, G., Schmale, H., \& Richter, D. (1982). Nucleotide sequence of cloned cDNA encoding bovine arginine vasopressin-neurophysin II precursor. Nature, 295(5847), 299-303. http://www.ncbi.nlm.nih.gov/pubmed/6276766

Maunsbach, A. B. (1966a). The influence of different fixatives and fixation methods on the ultrastructure of rat kidney proximal tubule cells. I. Comparison of different perfusion fixation methods and of glutaraldehyde, formaldehyde and osmium tetroxide fixatives. J Ultrastruct Res, 15(3), 242-282. https://doi.org/10.1016/s0022-5320(66)80109-

15 $\underline{0}$

Maunsbach, A. B. (1966b). The influence of different fixatives and fixation methods on the ultrastructure of rat kidney proximal tubule cells. II. Effects of varying osmolality, ionic strength, buffer system and fixative concentration of glutaraldehyde solutions. $J$ Ultrastruct Res, 15(3), 283-309. https://doi.org/10.1016/s0022-5320(66)80110-7

Meeker, R. B., Swanson, D. J., Greenwood, R. S., \& Hayward, J. N. (1991). Ultrastructural distribution of glutamate immunoreactivity within neurosecretory endings and pituicytes of the rat neurohypophysis. Brain Res, 564(2), 181-193. https://doi.org/10.1016/0006-8993(91)91454-9

Meeker, R. B., Swanson, D. J., \& Hayward, J. N. (1989). Light and electron microscopic localization of glutamate immunoreactivity in the supraoptic nucleus of the rat hypothalamus. Neuroscience, 33(1), 157-167. https://doi.org/10.1016/03064522(89)90318-7

Mills, F., Globa, A. K., Liu, S., Cowan, C. M., Mobasser, M., Phillips, A. G., Borgland, S. L., \& Bamji, S. X. (2017). Cadherins mediate cocaine-induced synaptic plasticity and behavioral conditioning. Nat Neurosci, 20(4), 540-549. https://doi.org/10.1038/nn.4503 
Morris, J. (2020). Neurosecretory Vesicles: Structure, Distribution, Release and Breakdown.

In G. Lemons JR and Dayanithi (Ed.), Neurosecretion: Secretory Mechanisms (Vol. 8, pp. 81-102). Springer Nature

Mouri, T., Itoi, K., Takahashi, K., Suda, T., Murakami, O., Yoshinaga, K., Andoh, N., Ohtani, H., Masuda, T., \& Sasano, N. (1993). Colocalization of corticotropin-releasing factor and vasopressin in the paraventricular nucleus of the human hypothalamus. Neuroendocrinology, 57(1), 34-39. https://doi.org/10.1159/000126339

Otubo, A., Kawakami, N., Maejima, S., Ueda, Y., Morris, J. F., Sakamoto, T., \& Sakamoto, H. (2020). Vasopressin gene products are colocalised with corticotrophin-releasing factor within neurosecretory vesicles in the external zone of the median eminence of the Japanese macaque monkey (Macaca fuscata). J Neuroendocrinol, 32(8), e12875. https://doi.org/10.1111/jne.12875

Rehbein, M., Hillers, M., Mohr, E., Ivell, R., Morley, S., Schmale, H., \& Richter, D. (1986). The neurohypophyseal hormones vasopressin and oxytocin. Precursor structure, synthesis and regulation. Biol Chem Hoppe Seyler, 367(8), 695-704. http://www.ncbi.nlm.nih.gov/pubmed/3768139

Satoh, K., Oti, T., Katoh, A., Ueta, Y., Morris, J. F., Sakamoto, T., \& Sakamoto, H. (2015). In vivo processing and release into the circulation of GFP fusion protein in arginine vasopressin enhanced GFP transgenic rats: response to osmotic stimulation. FEBS J, 282(13), 2488-2499. https://doi.org/10.1111/febs.13291

Sawchenko, P. E., Swanson, L. W., \& Vale, W. W. (1984). Co-expression of corticotropinreleasing factor and vasopressin immunoreactivity in parvocellular neurosecretory neurons of the adrenalectomized rat. Proc Natl Acad Sci U S A, 81(6), 1883-1887. https://www.ncbi.nlm.nih.gov/pubmed/6369332

25 Sun, D., Vingrys, A. J., \& Kalloniatis, M. (2007). Metabolic and functional profiling of the normal rat retina. $J$ Comp Neurol, 505(1), 92-113. https://doi.org/10.1002/cne.21478

Vale, W., Spiess, J., Rivier, C., \& Rivier, J. (1981). Characterization of a 41-residue ovine hypothalamic peptide that stimulates secretion of corticotropin and beta-endorphin. Science, 213(4514), 1394-1397. https://www.ncbi.nlm.nih.gov/pubmed/6267699

Valentino, R. J., Rudoy, C., Saunders, A., Liu, X. B., \& Van Bockstaele, E. J. (2001). Corticotropin-releasing factor is preferentially colocalized with excitatory rather than 
inhibitory amino acids in axon terminals in the peri-locus coeruleus region. Neuroscience, 106(2), 375-384. https://doi.org/10.1016/s0306-4522(01)00279-2

Walum, H., \& Young, L. J. (2018). The neural mechanisms and circuitry of the pair bond. Nat Rev Neurosci, 19(11), 643-654. https://doi.org/10.1038/s41583-018-0072-6

5 Wang, H., Ward, A. R., \& Morris, J. F. (1995). Oestradiol acutely stimulates exocytosis of oxytocin and vasopressin from dendrites and somata of hypothalamic magnocellular neurons. Neuroscience, 68(4), 1179-1188. https://doi.org/0306-4522(95)00186-M [pii]

Whitnall, M. H., Mezey, E., \& Gainer, H. (1985). Co-localization of corticotropin-releasing factor and vasopressin in median eminence neurosecretory vesicles. Nature, 317(6034), 248-250. https://www.ncbi.nlm.nih.gov/pubmed/3900740

Zhang, L., Hernandez, V. S., Zetter, M. A., \& Eiden, L. E. (2020). VGLUT-VGAT expression delineates functionally specialised populations of vasopressin-containing neurones including a glutamatergic perforant path-projecting cell group to the hippocampus in rat and mouse brain. $J$ Neuroendocrinol, 32(4), e12831. https://doi.org/10.1111/jne.12831

Ziegler, D. R., Cullinan, W. E., \& Herman, J. P. (2002). Distribution of vesicular glutamate transporter mRNA in rat hypothalamus. J Comp Neurol, 448(3), 217-229. https://doi.org/10.1002/cne.10257

20 Zimmerman, E. A., Carmel, P. W., Husain, M. K., Ferin, M., Tannenbaum, M., Frantz, A. G., \& Robinson, A. G. (1973). Vasopressin and neurophysin: high concentrations in monkey hypophyseal portal blood. Science, 182(4115), 925-927. https://doi.org/10.1126/science.182.4115.925 


\section{Posterior pituitary}

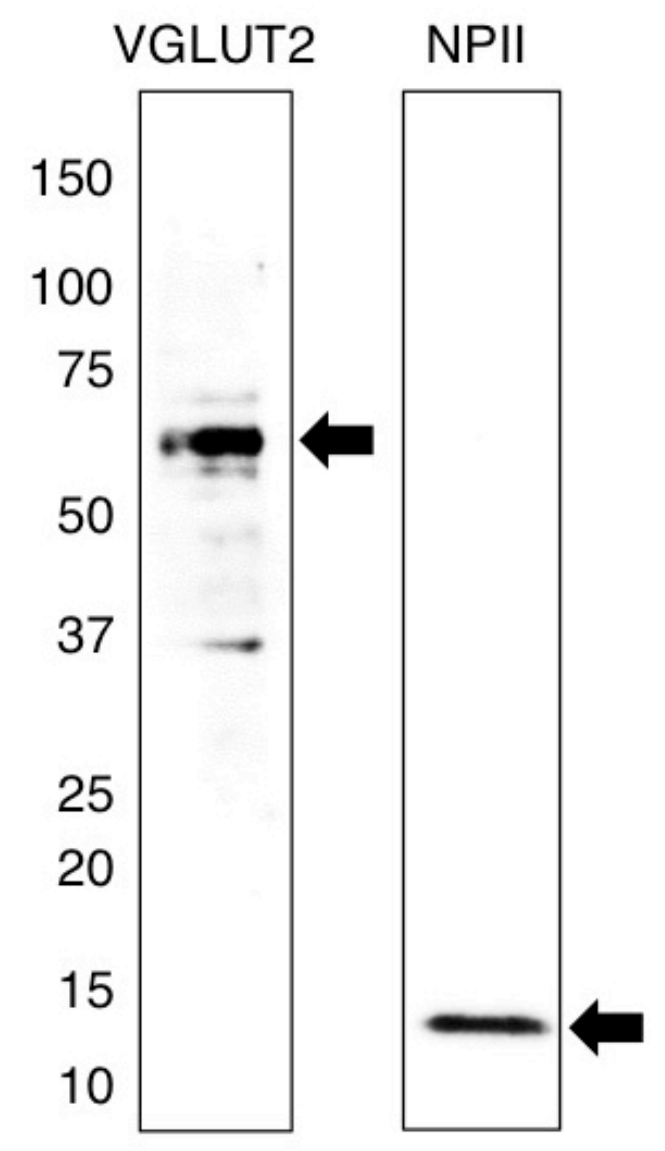

$5 \quad$ Figure 1. Western immunoblotting of vesicular glutamate transporter 2 (VGLUT2) and vasopressin-associated neurophysin (NPII). The number on the left indicates the molecular weight $(\mathrm{kDa})$. Extracts of protein from the posterior pituitary of the Japanese macaque monkey were transferred onto polyvinylidene difluoride membranes and probed with the guinea pig polyclonal antiserum against VGLUT2 or with the mouse monoclonal antibody against NPII. The antisera recognized a single major band at the expected molecular weight of VGLUT2 $(\sim 56 \mathrm{kDa})$ or NPII $(\sim 12 \mathrm{kDa})$ on a Western blot of the macaque posterior pituitary. 
bioRxiv preprint doi: https://doi org/10.1101/2021.06.07.447309; this version posted June 7, 2021. The copyright holder for this preprin (which was not certified by peer review) is the author/funder, who has granted bioRxiv a license to display the preprint in perpetuity. It is made available under aCC-BY 4.0 International license.
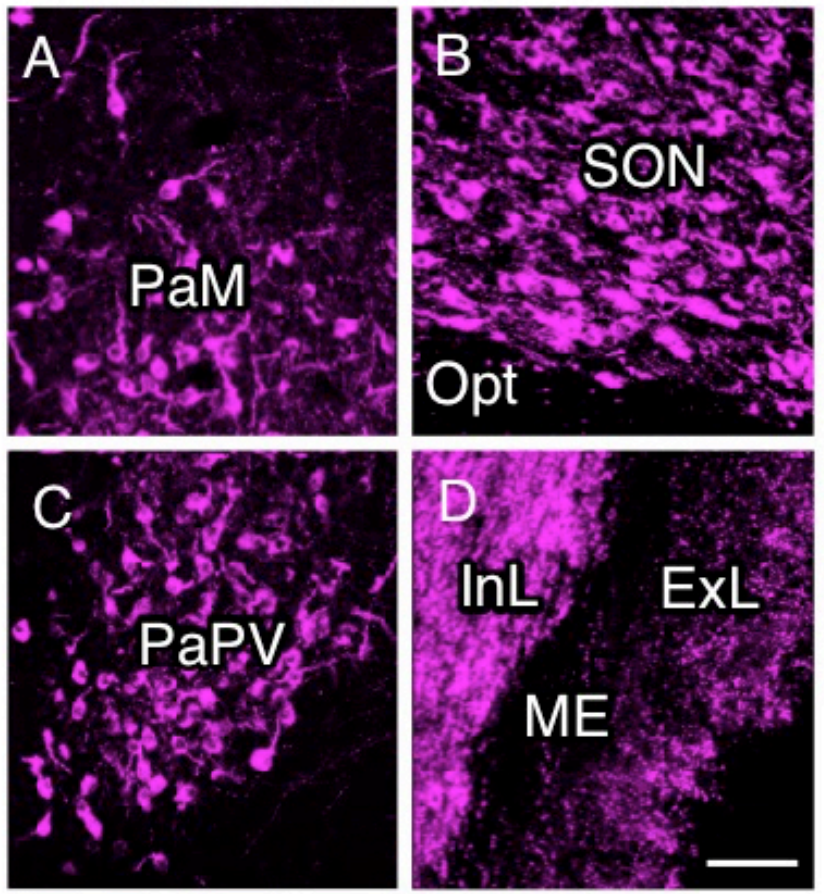

5 Figure 2. Immunofluorescence for vasopressin-associated neurophysin (NPII) in the macaque hypothalamus. NPII-immunoreactivity was observed in the paraventricular nucleus (PVN) of the hypothalamus; PaM, magnocellular part of the PVN (A); supraoptic nucleus (B); PaPV, parvocellular part of the PVN, ventral division (C); and median eminence (ME) (D). Opt, optic nerve; InL, internal layer of the ME; ExL, external layer of the ME. Scale bar, $100 \mu \mathrm{m}$. 


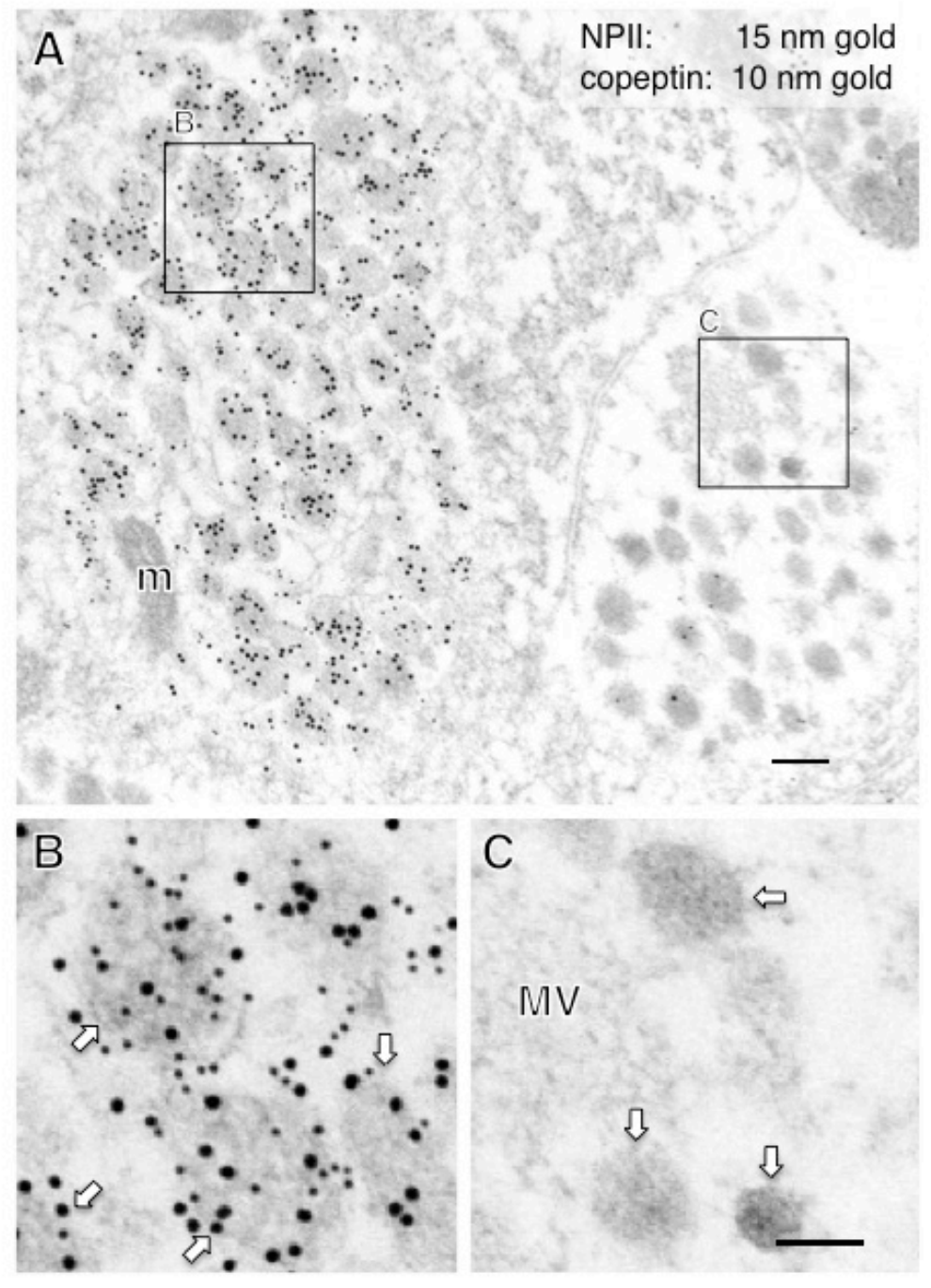

$5 \quad$ Figure 3. Double-label immunoelectron microscopy for vasopressin-associated neurophysin (NPII) and copeptin in the macaque posterior pituitary. Numerous neurosecretory vesicles located in some of the varicosities were doubly immunopositive for copeptin (10-nm gold particles) and NPII (15-nm gold particles). The outlined areas in (A) are enlarged in (B) and (C). In contrast, in other presumably oxytocin-containing varicosities, no NPII/copeptin-

10 immunoreactivity was detected (A and C). Scale bars, $200 \mathrm{~nm}$, and $100 \mathrm{~nm}$ in enlarged images. Arrows indicate dense-cored neurosecretory vesicles. m, mitochondrion; MV, clustered microvesicles. 
bioRxiv preprint doi: https://doi org/10.1101/2021.06.07.447309; this version posted June 7, 2021. The copyright holder for this preprint

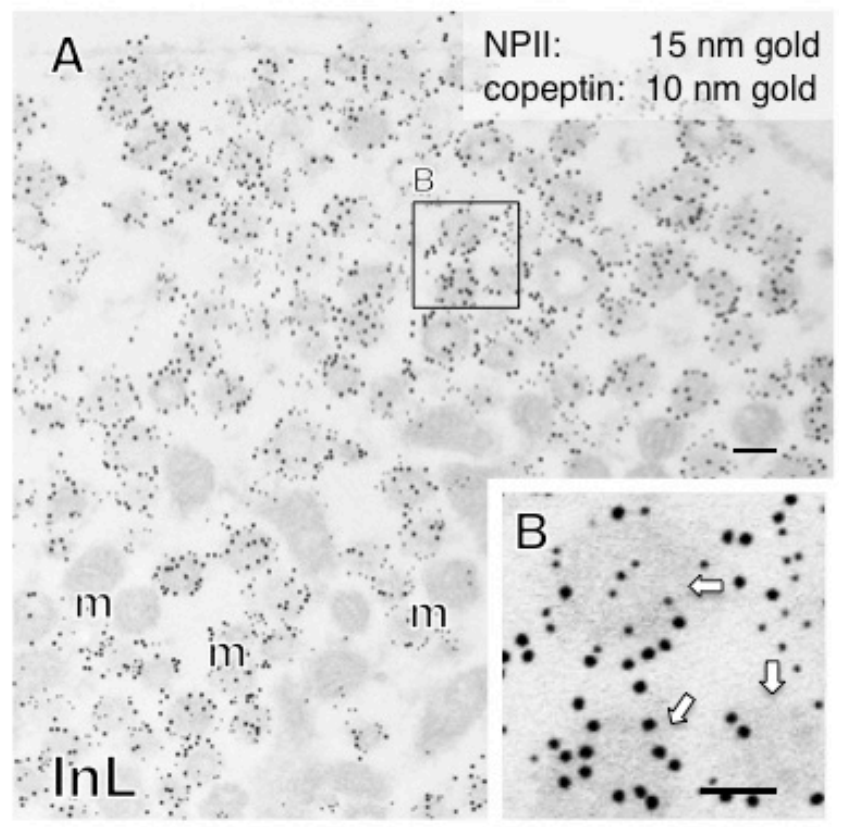

C

\section{MV}

MV
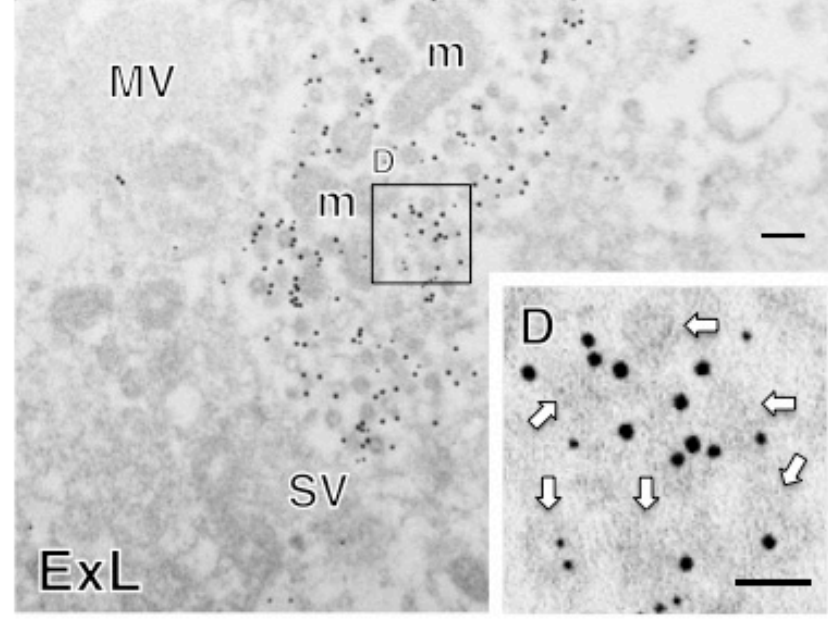

$5 \quad$ Figure 4. Double-label immunoelectron microscopy for vasopressin-associated neurophysin (NPII) and copeptin in the internal layer (InL; A, B) and external layer (ExL; C, D) of the macaque median eminence. Numerous dense-cored neurosecretory vesicles located in some of the varicosities were immunopositive for both copeptin (10-nm gold particles) and NPII (15-nm gold particles). The outlined area in (A) and (C) is enlarged in (B) and (D), respectively. Scale bars, $200 \mathrm{~nm}$, and $100 \mathrm{~nm}$ in enlarged images. Arrows indicate densecored neurosecretory vesicles. m, mitochondrion; MV, clustered microvesicles. 


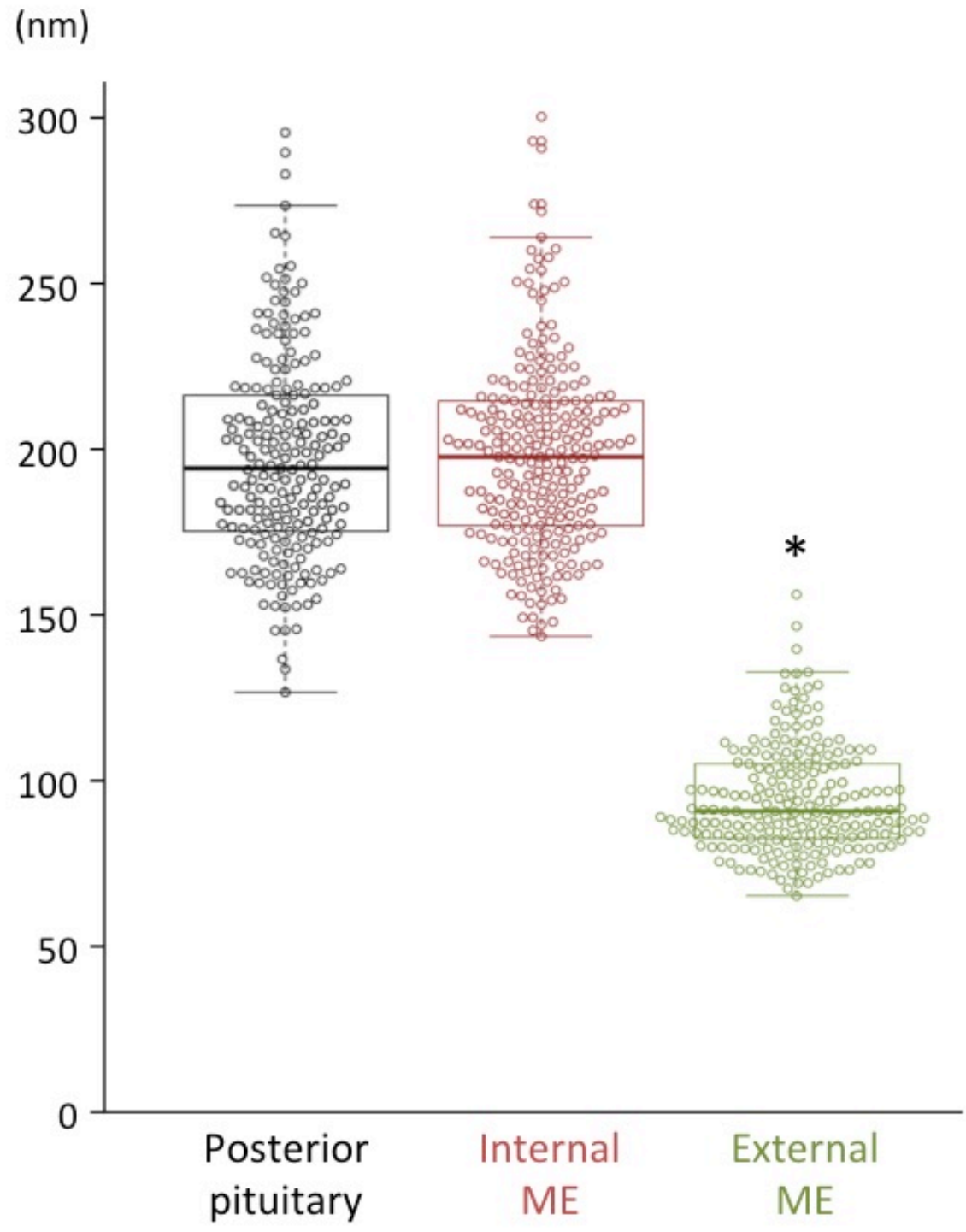

$5 \quad$ Figure 5. Bee-swarm and box plots displaying the major axis of dense-cored neurosecretory vesicles distributed in the posterior pituitary (black), internal layer of the median eminence (ME) (red), and external layer of the ME (green) in macaque monkeys. The major axis of dense-cored vesicles in the posterior pituitary and the internal layer of the $\mathrm{ME}(\sim 200 \mathrm{~nm})$ was significantly larger than that of the vesicles in the external layer of the $\mathrm{ME}(\sim 100 \mathrm{~nm}) .{ }^{*} P<$ $10 \quad 0.05, v s$. posterior pituitary and internal layer of the ME. 


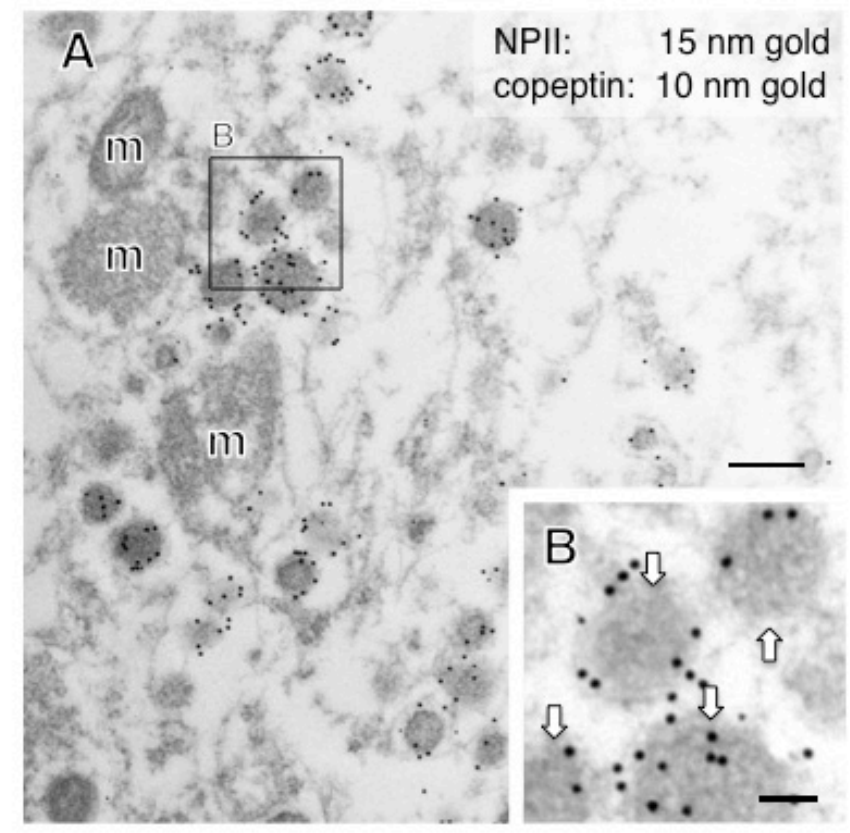

$5 \quad$ Figure 6. Double-label immunoelectron microscopy for vasopressin-associated neurophysin (NPII) and copeptin in the macaque supraoptic nucleus (SON). Many dense-cored neurosecretory vesicles located in the cell body were doubly immunopositive for copeptin (10-nm gold particles) and NPII (15-nm gold particles). The outlined area in (A) is enlarged in (B). Scale bars, $200 \mathrm{~nm}$, and $100 \mathrm{~nm}$ in the enlarged image. Arrows indicate dense-cored neurosecretory vesicles. $\mathrm{m}$, mitochondrion. 
bioRxiv preprint doi: https://doi org/10.1101/2021.06.07.447309; this version posted June 7, 2021. The copyright holder for this preprint
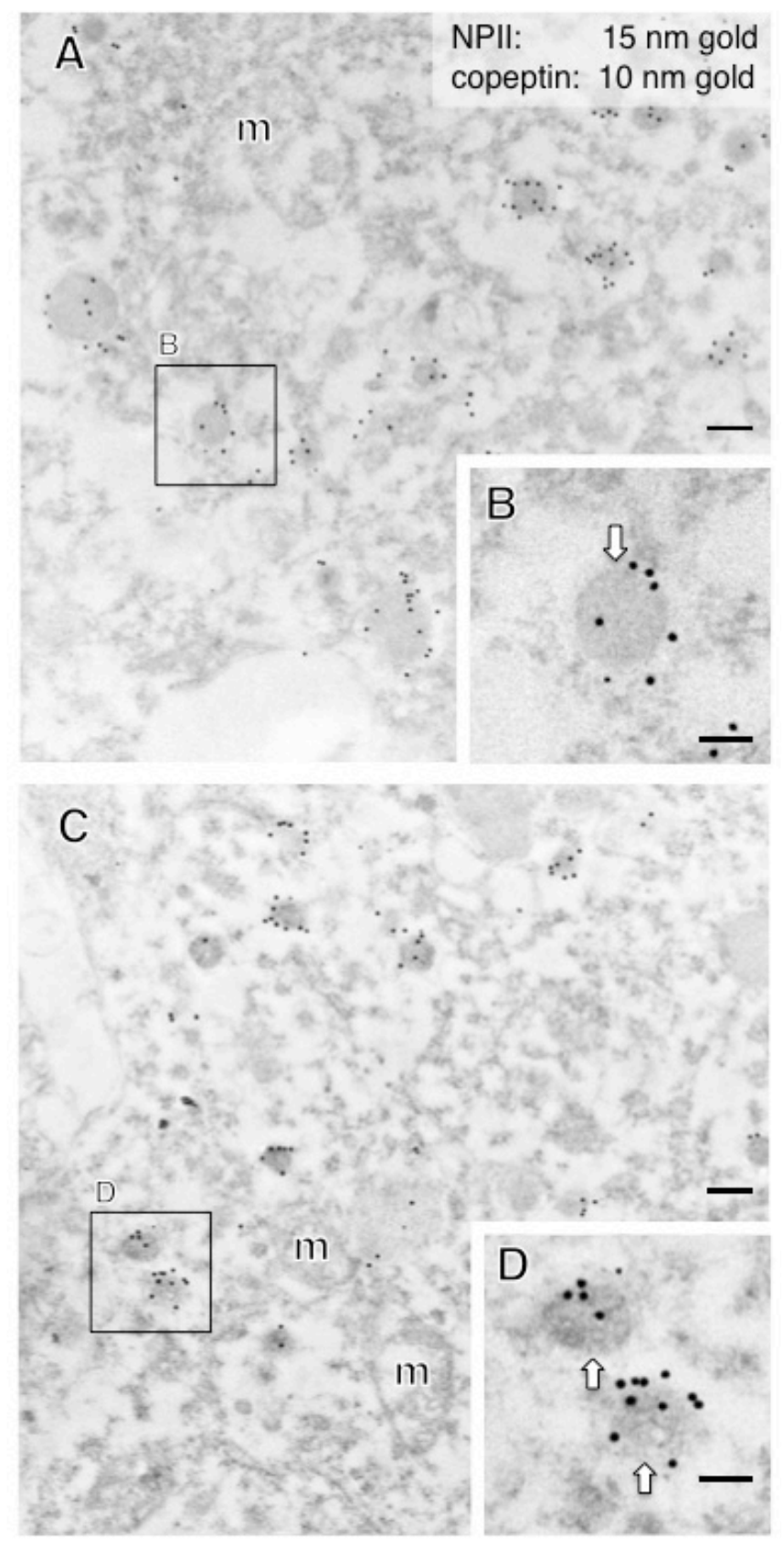

$5 \quad$ Figure 7. Double-label immunoelectron microscopy for vasopressin-associated neurophysin (NPII) and copeptin in the macaque paraventricular nucleus (PVN) of the hypothalamus. (A) In the cell body of a putative magnocellular vasopressin neuron, many dense-cored neurosecretory vesicles located in the cell body were doubly immunopositive for copeptin (10-nm gold particles) and NPII (15-nm gold particles). (C) Similar results are obtained in the cell body of a putative parvocellular vasopressin neuron. The size of dense-cored vesicles in (A and B) was larger than that of vesicles in (C and D). The outlined areas are enlarged. Scale bars, $200 \mathrm{~nm}$, and $100 \mathrm{~nm}$ in enlarged images. Arrows indicate dense-cored neurosecretory vesicles. $\mathrm{m}$, mitochondrion. 

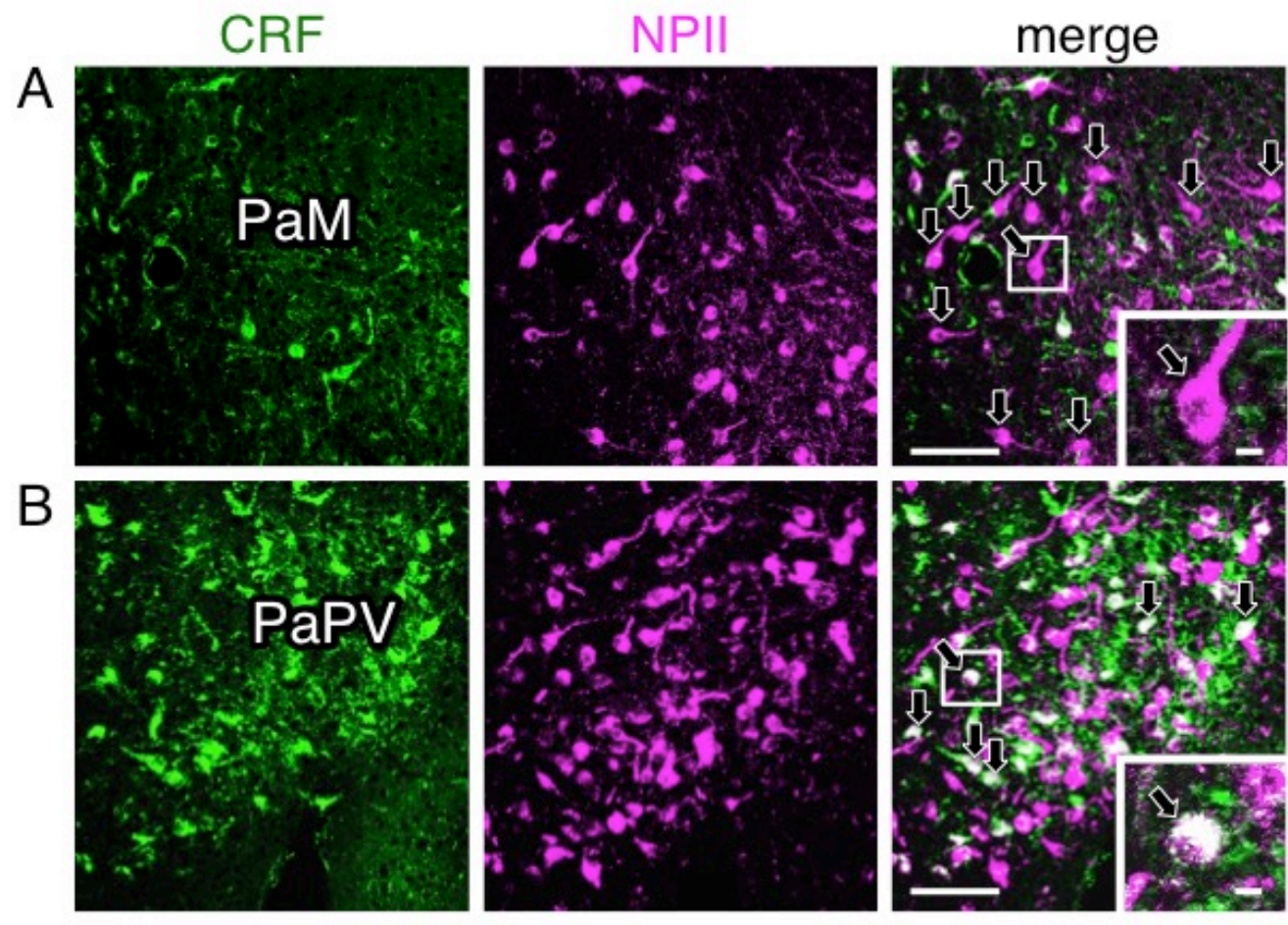

$5 \quad$ Figure 8. Double-label immunofluorescence for corticotrophin-releasing factor (CRF) and vasopressin-associated neurophysin (NPII) in the paraventricular nucleus (PVN) of the macaque hypothalamus; PaM, magnocellular part of the PVN (A); PaPV, parvocellular part of the PVN, ventral division (B). Immunoreactivity against CRF (green) and NPII (magenta) is merged in each right-hand panel (overlap; white). The outlined areas in merged images are enlarged. Arrows in (A; merged) indicate perikarya single-immunopositive for NPII in the PaM. Arrows in (B; merged) indicate doubly immunopositive for CRF and NPII in the PaPV. Scale bars, $100 \mu \mathrm{m}$, and $10 \mu \mathrm{m}$ in enlarged images. 
bioRxiv preprint doi: https://doi.org/10.1101/2021.06.07.447309; this version posted June 7, 2021. The copyright holder for this preprint (which was not certified by peer review) is the author/funder, who has granted bioRxiv a license to display the preprint in perpetuity. It is made available under aCC-BY 4.0 International license.
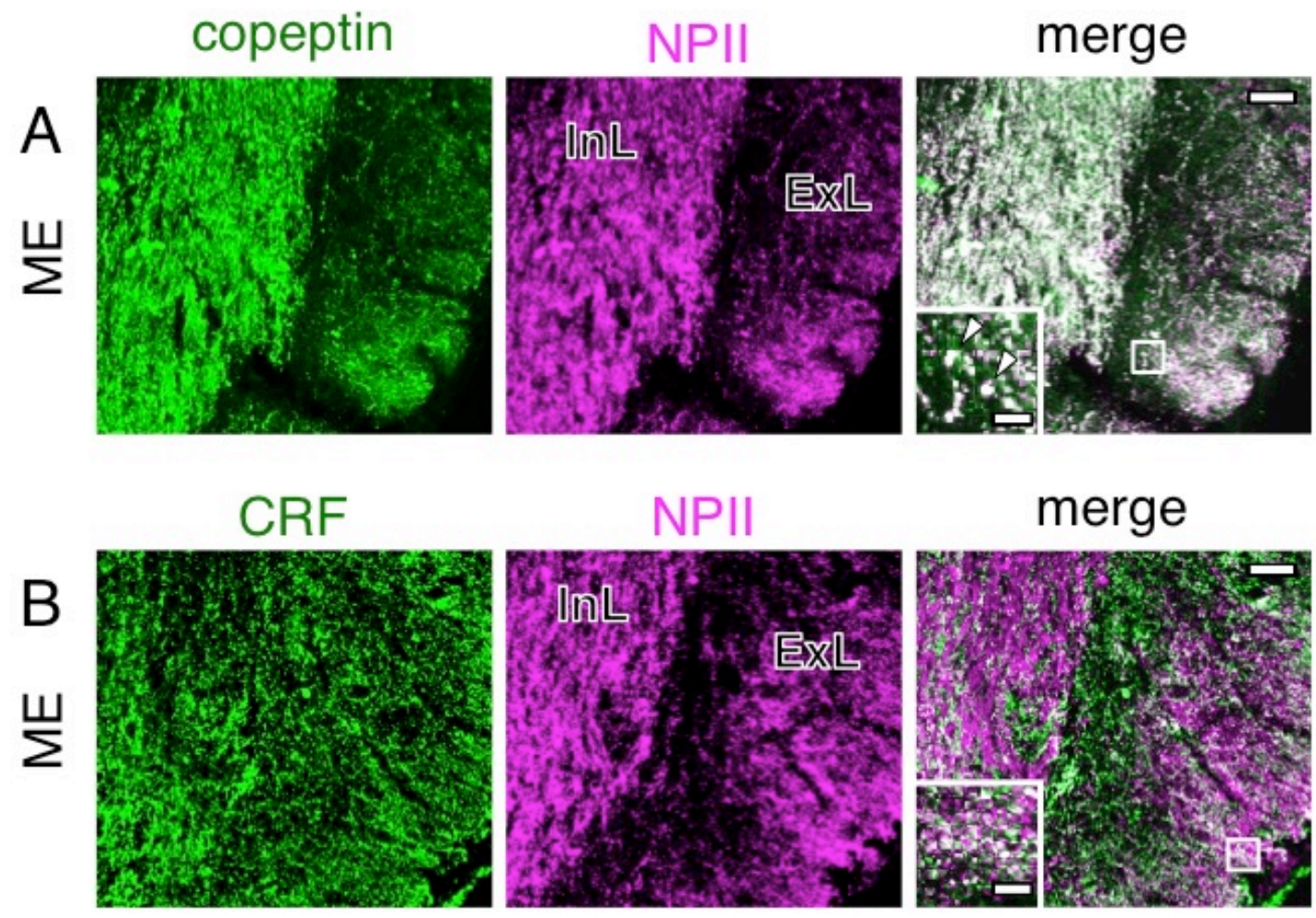

$5 \quad$ Figure 9. Double-label immunofluorescence for copeptin (A) or corticotrophin-releasing factor (CRF) (B) and vasopressin-associated neurophysin (NPII) in the macaque median eminence (ME). Immunoreactivity against copeptin (A; green) or CRF (B; green) and NPII (magenta) is merged in each right-hand panel (overlap; white). The outlined areas in merged images are enlarged. Arrowheads in (A) indicate tissue doubly immunopositive for copeptin and NPII. Scale bars, $50 \mu \mathrm{m}$, and $10 \mu \mathrm{m}$ in enlarged images. InL, internal layer of the ME; ExL, external layer of the ME. 


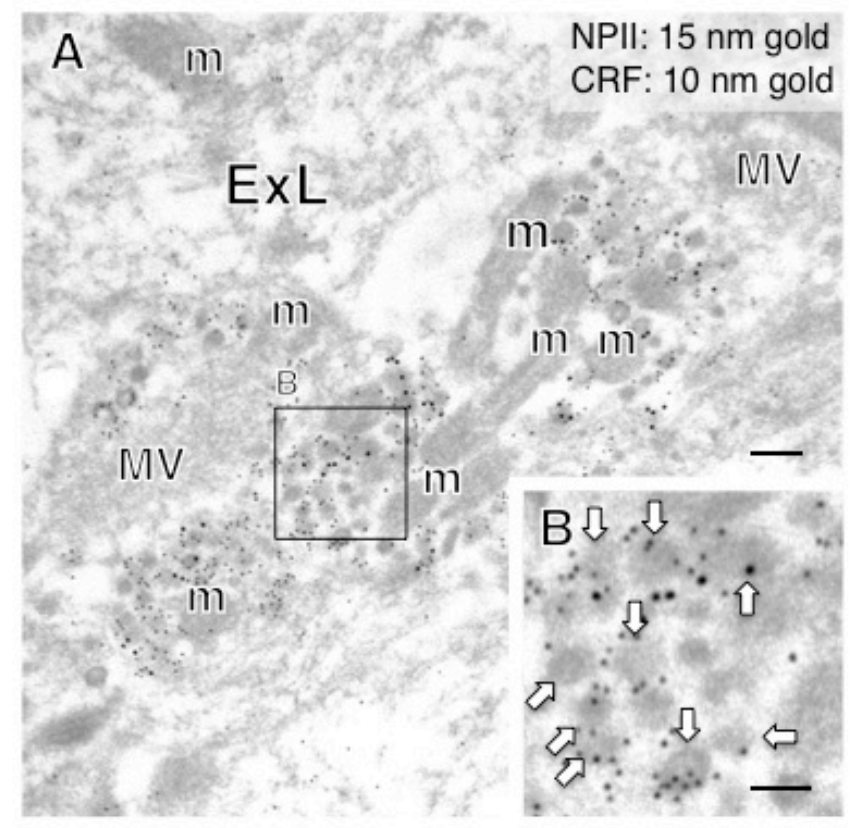

$5 \quad$ Figure 10. Double-label immunoelectron microscopy for vasopressin-associated neurophysin (NPII) and corticotrophin-releasing factor (CRF) in the external layer (ExL) of the macaque median eminence. In some axonal varicosities, numerous dense-cored neurosecretory vesicles were doubly immunopositive for CRF (10-nm gold particles) and NPII (15-nm gold particles). The outlined area in (A) is enlarged in (B). Scale bars, $200 \mathrm{~nm}$, and $100 \mathrm{~nm}$ in the enlarged

10 image. Arrows indicate dense-cored neurosecretory vesicles. m, mitochondrion; MV, clustered microvesicles. 


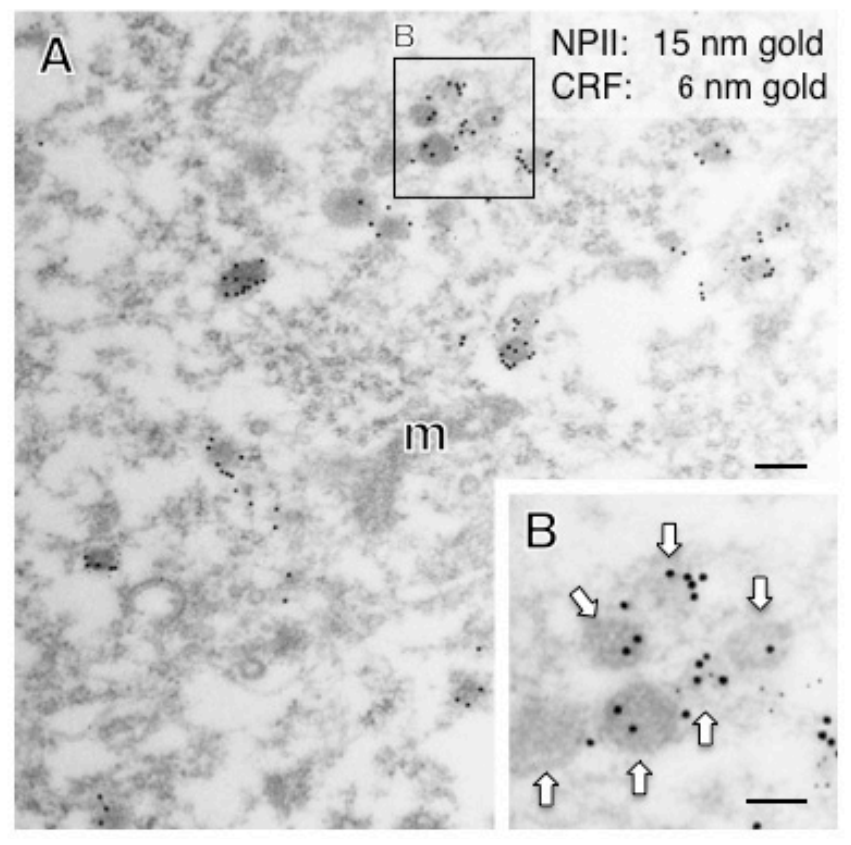

$5 \quad$ Figure 11. Double-label immunoelectron microscopy for vasopressin-associated neurophysin (NPII) and corticotropin-releasing factor (CRF) in the paraventricular nucleus (PVN) of the hypothalamus in a macaque monkey. (A) In the cell body of a possible parvocellular vasopressin neuron, many dense-cored neurosecretory vesicles located in the cell body were doubly immunopositive for CRF (6-nm gold particles) and NPII (15-nm gold particles). The

10 outlined area in (A) is enlarged in (B). Scale bars, $200 \mathrm{~nm}$, and $100 \mathrm{~nm}$ in the enlarged image. Arrows indicate dense-cored neurosecretory vesicles. m, mitochondrion. 
bioRxiv preprint doi: https://doi.org/10.1101/2021.06.07.447309; this version posted June 7, 2021. The copyright holder for this preprint (which was not certified by peer review) is the author/funder, who has granted bioRxiv a license to display the preprint in perpetuity. It is made available under aCC-BY 4.0 International license.
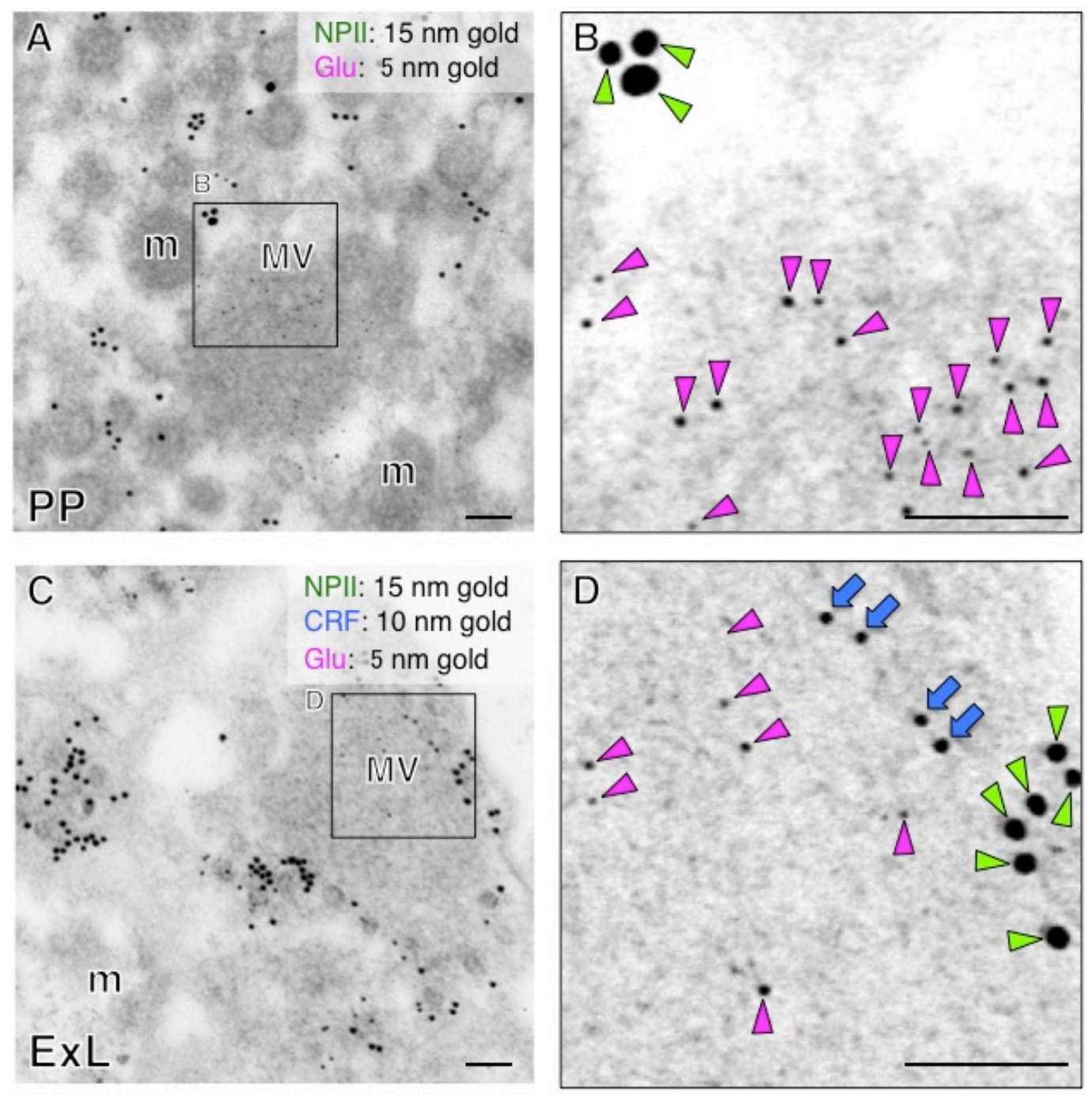

$5 \quad$ Figure 12. Immunoelectron microscopy for glutamate (Glu) in the posterior pituitary (PP) (A) and external layer of the median eminence $(\operatorname{ExL})(\mathrm{C})$ in a macaque monkey. (B) Doublelabel immunoelectron microscopy for vasopressin-associated neurophysin (NPII) and Glu shows that Glu-immunoreactivity is associated with microvesicles in the macaque posterior pituitary. (D) Triple-label immunoelectron microscopy for corticotrophin-releasing factor (CRF)/NPII/Glu indicates that Glu-immunoreactivity is associated with electron-lucent small vesicles in the axonal endings, in the NPII/CRF-double positive endings. The outlined areas are enlarged. Scale bars, $100 \mathrm{~nm}$. Blue arrows indicate NPII-immunoreactivity; Green arrowheads indicate CRF-immunoreactivity. Magenta arrowheads indicate Gluimmunoreactivity. m, mitochondrion; MV, clustered microvesicles. 
bioRxiv preprint doi: https://doi.org/10.1101/2021.06.07 447309; this version posted June 7, 2021. The copyright holder for this preprint (which was not certified by peer review) is the author/funder, who has granted bioRxiv a license to display the preprint in perpetuity. It is made available under aCC-BY 4.0 International license.
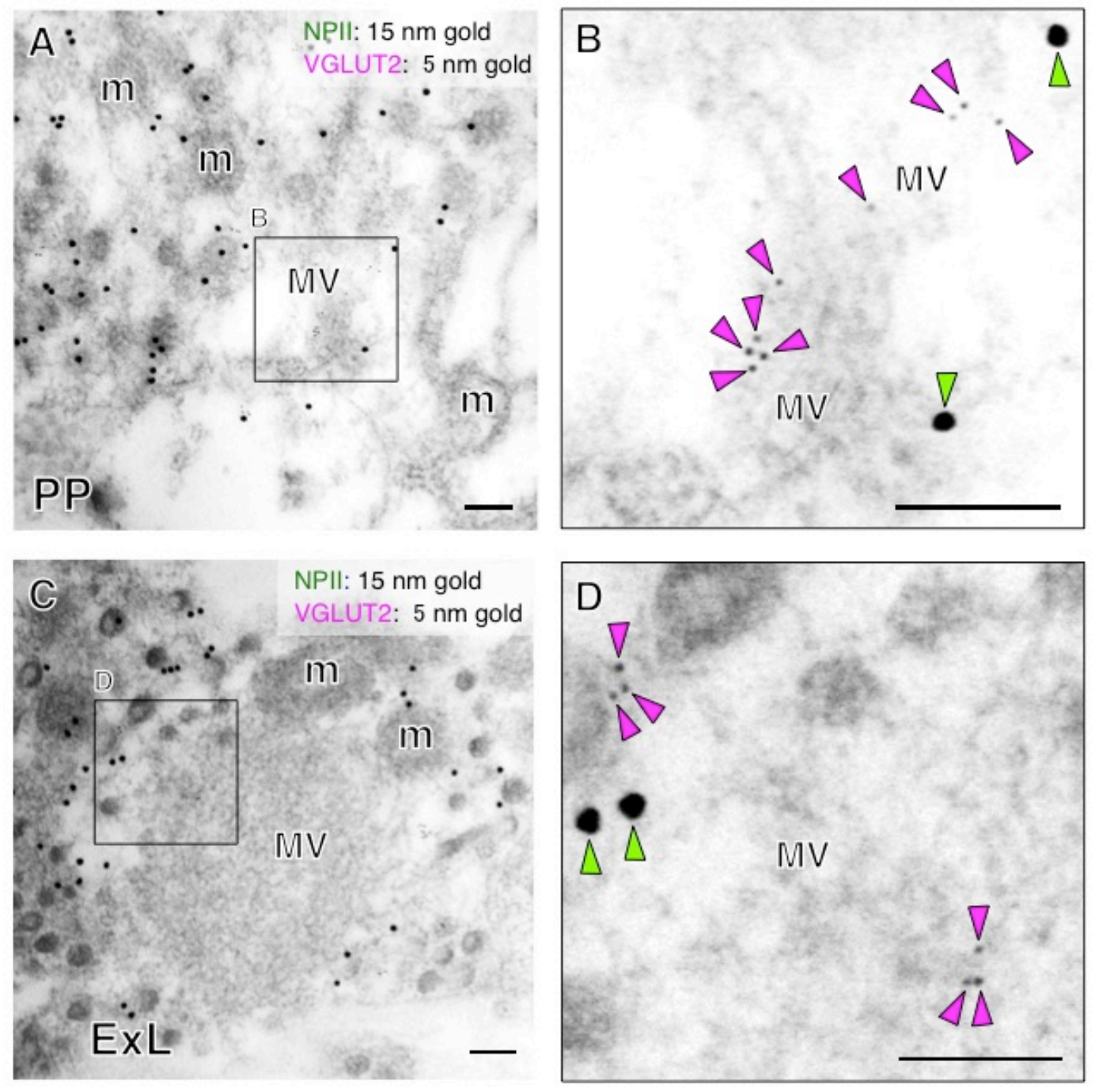

$5 \quad$ Figure 13. Immunoelectron microscopy for vesicular glutamate transporter 2 (VGLUT2) in the posterior pituitary (PP) (A) and external layer of the median eminence $($ ExL) $(C)$ in a macaque monkey. (B) Double-label immunoelectron microscopy for vasopressin-associated neurophysin (NPII) and VGLUT2 shows that VGLUT2-immunoreactivity is associated with clustered microvesicles (MV) in the posterior pituitary. (D) Double-label immunoelectron microscopy for NPII/VGLUT2 indicates that VGLUT2-immunoreactivity is associated with the membrane of electron-lucent small vesicles in the vasopressin endings. The outlined areas are enlarged. Scale bars, $100 \mathrm{~nm}$. Green arrowheads indicate NPII-immunoreactivity; Magenta arrowheads indicate VGLUT2-immunoreactivity. m, mitochondrion; MV, clustered microvesicles. 
bioRxiv preprint doi: https://doi.org/10.1101/2021.06.07.447309; this version posted June 7, 2021. The copyright holder for this preprint (which was not certified by peer review) is the author/funder, who has granted bioRxiv a license to display the preprint in perpetuity. It is made available under aCC-BY 4.0 International license.

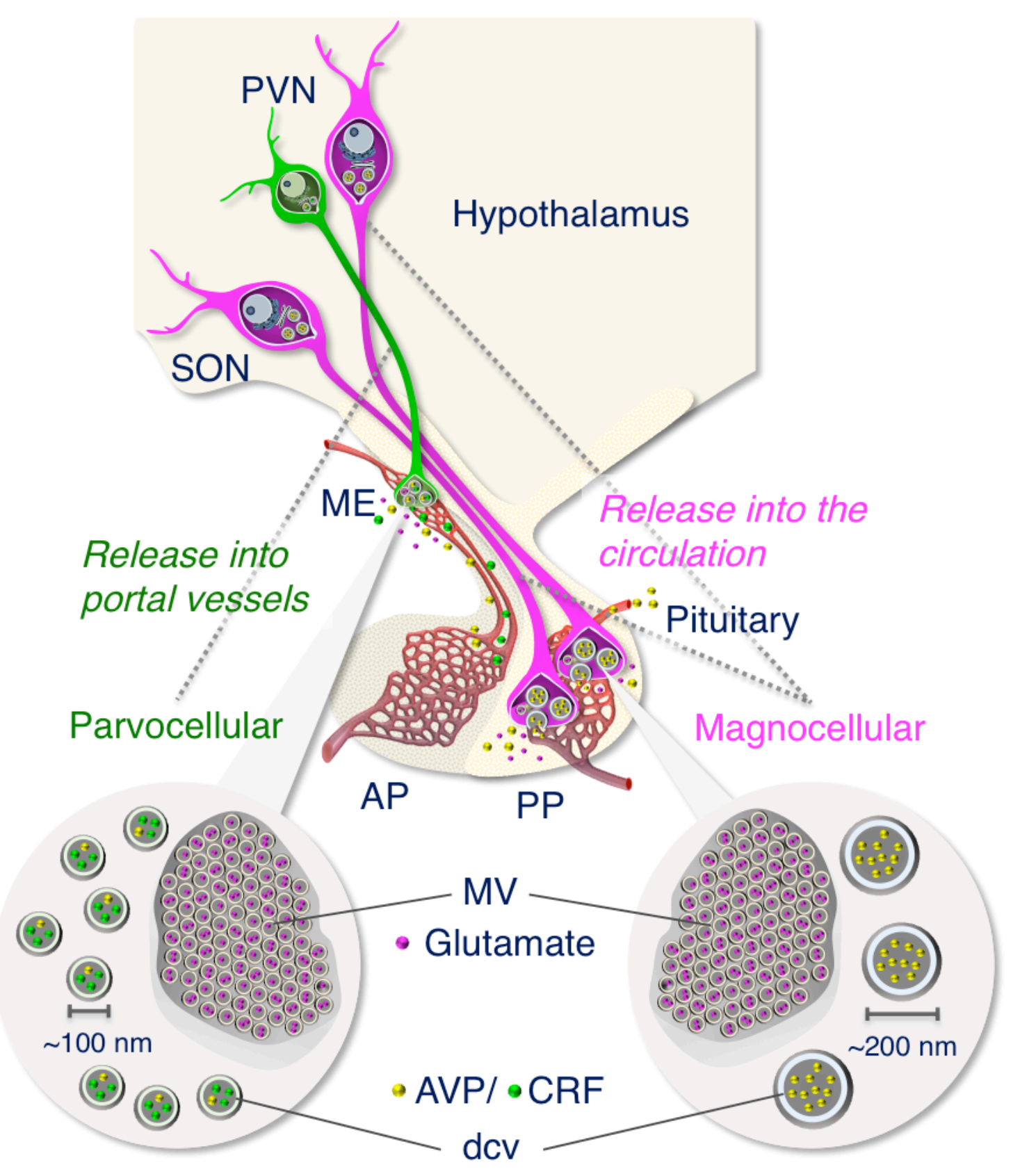

$5 \quad$ Figure 14. Working model showing that the size difference in dense-cored neurosecretry vesicles $(\mathrm{dcv})$ between magnocellular $(\sim 200 \mathrm{~nm})$ and parvocellular $(\sim 100 \mathrm{~nm})$ vasopressin (AVP)- and/or corticotrophin-releasing factor (CRF)-producing neurons in the hypothalamus of the Japanese macaque monkey. We also demonstrate that both magno- and parvocellular AVP/CRF neurons are glutamatergic in primates. AP, anterior pituitary; ME, median

10 eminence; MV, clustered microvesicles; PP, posterior pituitary; PVN, paraventricular nucleus; SON, supraoptic nucleus. 


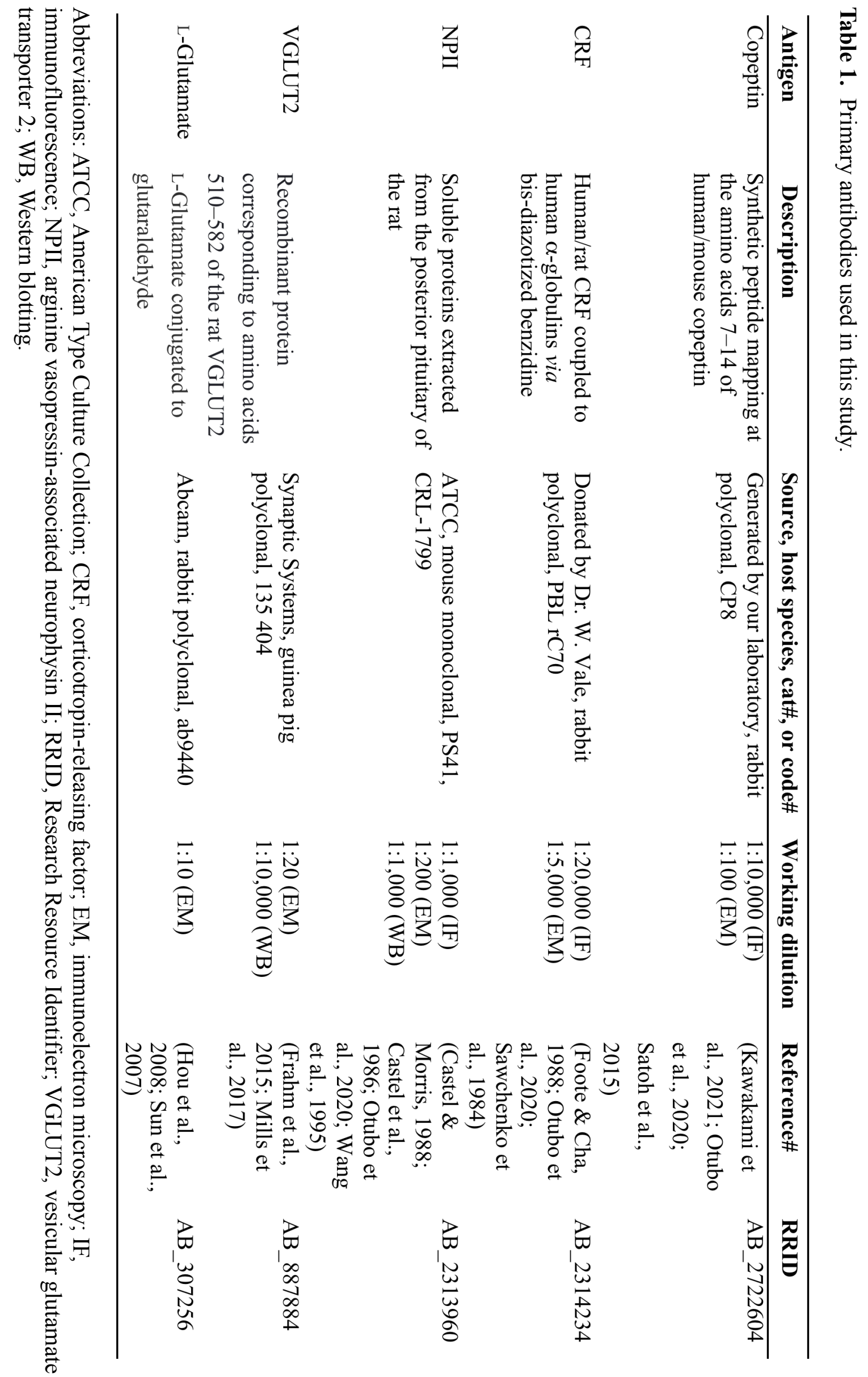


Table 2. Identification of cell types (magno- or parvocellular neurons) based on the major axis of dense-cored neurosecretory vesicles.

\begin{tabular}{lllll}
\hline Region & Major axis $(\mathrm{nm})$ & $\begin{array}{l}\text { Magno or } \\
\text { parvo }\end{array}$ & $\begin{array}{l}\text { Number of } \\
\text { vesicles examined }\end{array}$ & Identification \\
\hline Posterior pituitary & $196 \pm 2$ & Magno & 205 & AVP \\
\hline Internal ME & $197 \pm 2$ & Magno & 237 & AVP without CRF \\
\hline External ME & $93 \pm 1^{*}$ & Parvo & 212 & CRF \\
\hline
\end{tabular}

5 AVP, arginine vasopressin; Internal ME, internal layer of the median eminence; CRF, corticotrophin-releasing factor; External ME, external layer of the median eminence. ${ }^{*} P<$ $0.05, v s$. posterior pituitary and internal ME. All data values are presented as mean \pm standard error of the mean (SEM). 
Table 3. Characterization of cell types (magno- or parvocellular neurons) based on the major axis of dense-cored neurosecretory vesicles.

\begin{tabular}{|c|c|c|c|c|c|}
\hline $\begin{array}{l}\text { Cell } \\
\text { body }\end{array}$ & Major axis (nm) & Magno or parvo & $\begin{array}{l}\text { Number of } \\
\text { vesicles examined }\end{array}$ & $\begin{array}{l}\text { SON or } \\
\text { PVN }\end{array}$ & Identification \\
\hline$\# 1$ & $187 \pm 5^{*}$ & Magno & 29 & SON & AVP \\
\hline$\# 2$ & $175 \pm 6^{*}$ & Magno & 35 & SON & AVP \\
\hline$\# 3$ & $189 \pm 10^{*}$ & Magno & 24 & SON & AVP \\
\hline$\# 4$ & $181 \pm 5^{*}$ & Magno & 26 & SON & AVP \\
\hline$\# 5$ & $171 \pm 7 *$ & Magno & 25 & SON & AVP \\
\hline \#6 & $195 \pm 6^{*}$ & Magno & 30 & SON & AVP \\
\hline \#7 & $205 \pm 6^{*}$ & Magno & 46 & SON & AVP \\
\hline$\# 8$ & $188 \pm 5^{*}$ & Magno & 49 & PVN & AVP \\
\hline$\# 9$ & $170 \pm 5^{*}$ & Magno & 20 & PVN & AVP \\
\hline$\# 10$ & $169 \pm 8 *$ & Magno & 22 & PVN & AVP \\
\hline$\# 11$ & $172 \pm 4^{*}$ & Magno & 24 & PVN & AVP \\
\hline$\# 12$ & $184 \pm 5^{*}$ & Magno & 25 & PVN & AVP \\
\hline$\# 13$ & $182 \pm 5 \dagger$ & Magno & 21 & PVN & AVP \\
\hline$\# 14$ & $103 \pm 5 \dagger$ & Parvo & 38 & PVN & AVP \\
\hline$\# 15$ & $98 \pm 4 \dagger$ & Parvo & 42 & PVN & $\mathrm{CRF}$ \\
\hline$\# 16$ & $109 \pm 4 \dagger$ & Parvo & 51 & PVN & $\mathrm{CRF}$ \\
\hline$\# 17$ & $93 \pm 5 \dagger$ & Parvo & 24 & PVN & $\mathrm{CRF}$ \\
\hline$\# 18$ & $107 \pm 5 \dagger$ & Parvo & 40 & PVN & $\mathrm{CRF}$ \\
\hline$\# 19$ & $103 \pm 4 \uparrow$ & Parvo & 35 & PVN & $\mathrm{CRF}$ \\
\hline$\# 20$ & $110 \pm 7 \dagger$ & Parvo & 42 & PVN & $\mathrm{CRF}$ \\
\hline$\# 21$ & $108 \pm 5 \dagger$ & Parvo & 77 & PVN & $\mathrm{CRF}$ \\
\hline$\# 22$ & $93 \pm 4 \dagger$ & Parvo & 81 & PVN & CRF \\
\hline$\# 23$ & $95 \pm 5 \dagger$ & Parvo & 30 & PVN & $\mathrm{CRF}$ \\
\hline$\# 24$ & $120 \pm 6^{* \dagger}$ & (Parvo) & 40 & PVN & $\mathrm{CRF}$ \\
\hline$\# 25$ & $113 \pm 3 * \dagger$ & (Parvo) & 89 & PVN & $\mathrm{CRF}$ \\
\hline
\end{tabular}

5 AVP, arginine vasopressin; CRF, corticotrophin-releasing factor; SON, supraoptic nucleus; PVN, paraventricular nucleus. $* P<0.05$, vs. external layer of the median eminence; $\uparrow P<$ $0.05, v s$. posterior pituitary and internal layer of the median eminence. All data values are presented as mean \pm standard error of the mean (SEM). 